\title{
Unmasking Inequality: STEM Course Experience During the COVID-19 Pandemic
}

Barbara Means \& Julie Neisler August 2020
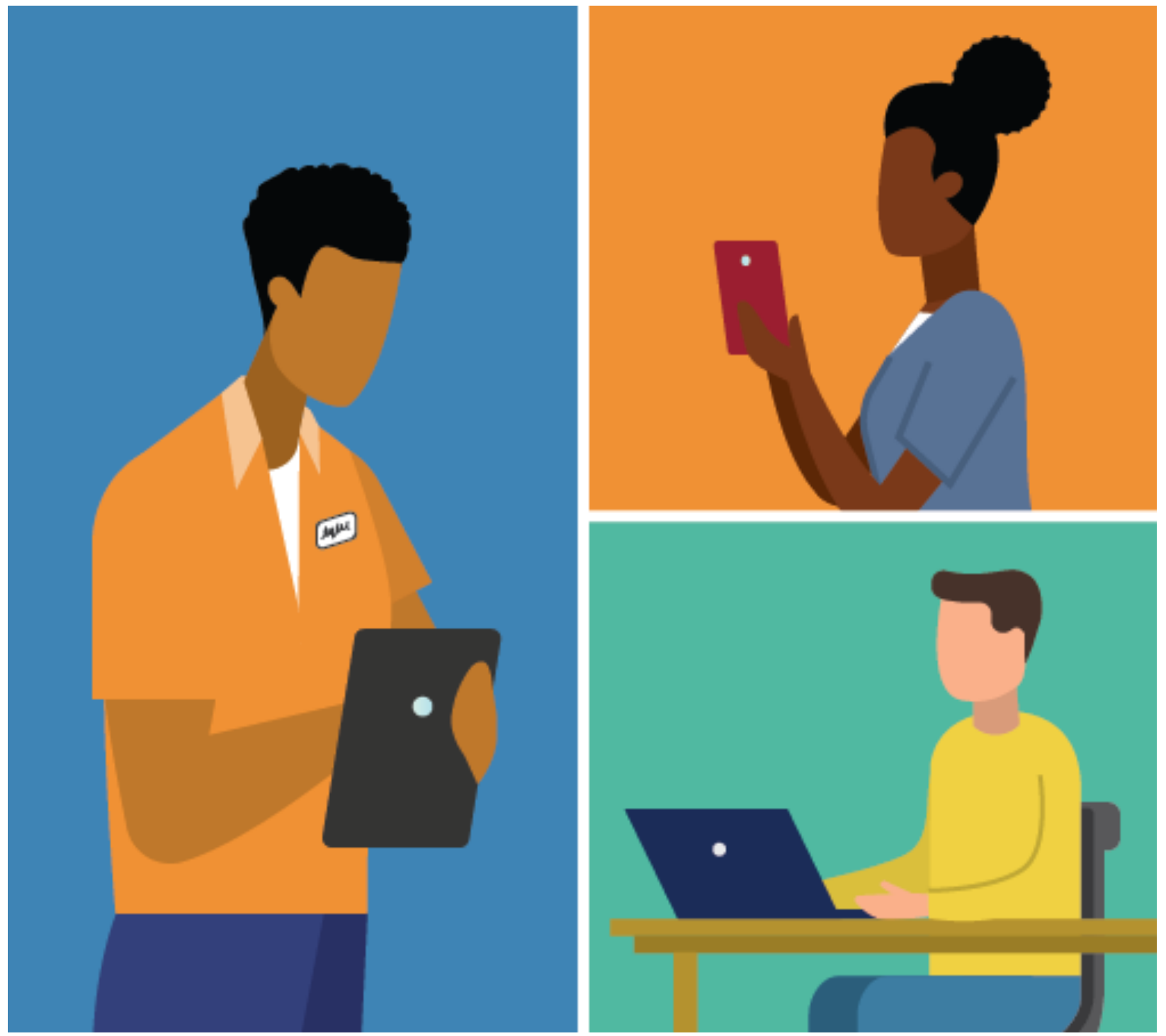

Digital Promise 


\section{Suggested Citation}

Means, B., \& Neisler, J. (2020). Unmasking Inequality: STEM Course Experiences During the COVID-19 Pandemic. Digital Promise Global.

\section{Acknowledgements}

This work was supported by a grant from the National Science Foundation (DUE 2029642). Any opinions, findings, conclusions, or recommendations are those of the authors and do not necessarily reflect the position, policy, or endorsement of their organization or the funding agency.

We are grateful to the many colleagues who have generously shared their insights concerning the most important issues in learning online during the pandemic. These include Connie Della Piana of the National Science Foundation, Jessica Rowland Williams of the Every Learner Everywhere Network, Pati Ruiz of Digital Promise, Kristen Fox of Tyton Partners, Karen Vignare and Megan Tesene of the Association of Public and Land-grant Universities, and Ruanda Garth-McCullough of Achieving the Dream.

\section{Contact Information}

Email: bmeans@digitalpromise.org

Digital Promise:

Washington, DC:

1001 Connecticut Avenue NW, Suite 935

Washington, DC 20036

\section{San Mateo, CA:}

2955 Campus Dr. Suite 110

San Mateo, CA 94403

Website: https://digitalpromise.org/

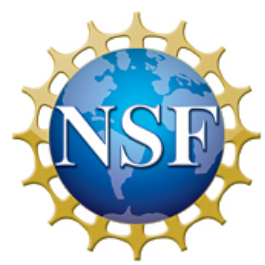




\section{Contents}

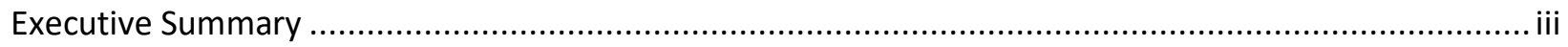

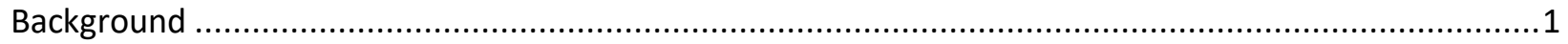

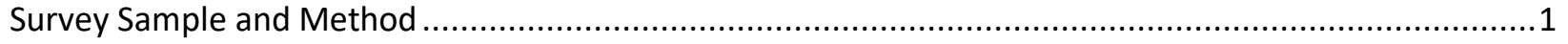

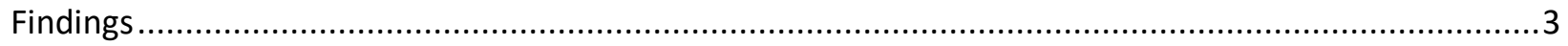

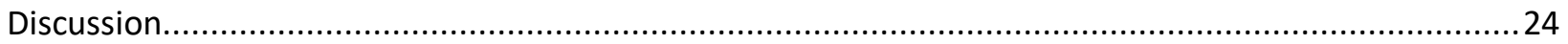

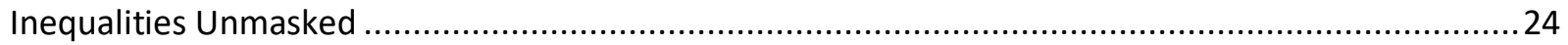

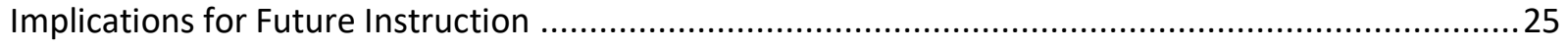

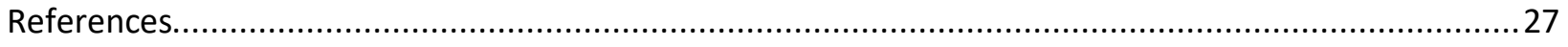

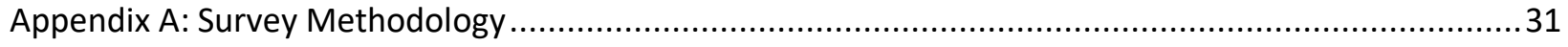

Appendix B: Survey Items and Response Distribution................................................................. 34

\section{List of Tables and Figures}

Figure 1. Satisfaction with their course before and after the move to remote instruction ......................6

Figure 2. Student satisfaction with quality of four dimensions of their online course ........................... 7

Figure 3. Comparison of student experiences in their course before and after the shift to remote

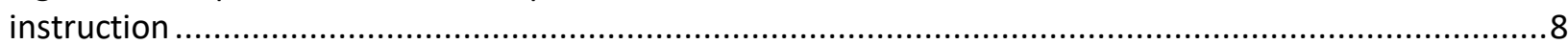

Figure 4. Severity of various problems with online course participation ........................................... 12

Table 1. Student satisfaction with course overall and with how well they were learning by number of challenges experienced..

Table 2. Number of major challenges experienced in continuing their STEM course online, by student

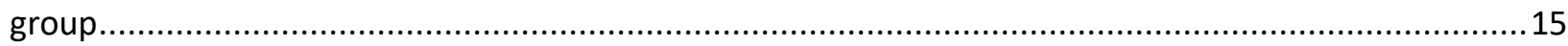

Table 3. Frequency of major problems trying to learn online for selected race/ethnicity groups ............16

Table 4. Frequency of major problems trying to learn online by race/ethnicity catrgory .......................17

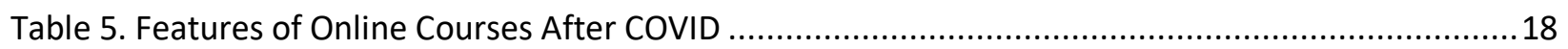

Table 6. Percentage of students reporting each instructional practice, by course subject area ...............20

Figure 5. Satisfaction with Post-COVID course by number of recommended online practices used in

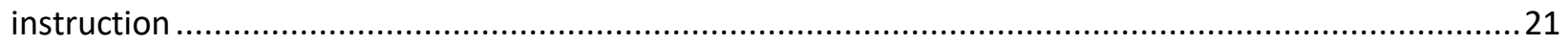

Table 7. Frequency of recommended online instructional practices by institution type........................23

Figure 6. Aspects of their STEM course experience judged equivalent or better online by student race/ethnicity 


\section{Executive Summary}

This report describes the experiences of over 600 undergraduates who were taking STEM courses with in-person class meetings that had to shift to remote instruction in spring 2020 because of COVID-19. Survey data were collected through a national, random-sample survey conducted May 13 to June 1, 2020.

Compared to students taking courses in non-STEM subjects, students taking STEM courses reported lower levels of satisfaction with their courses both before and after the move to remote instruction. For both kinds of courses, course satisfaction levels were much lower after courses moved online. Aspects of the course experience that most students thought were worse online than before were opportunities to collaborate with other students, interest level of the course content, and feeling included as a member of the class.

Internet connectivity issues were serious enough to interfere with students' ability to attend or participate in their STEM course at least occasionally for $46 \%$ of students, with $15 \%$ of students experiencing such problems often or very often. Almost a quarter of students taking STEM courses (23\%) reported experiencing hardware or software problems serious enough to impact their ability to attend or participate in their STEM course at least occasionally with 7\% reporting that they had such problems often or very often.

A large majority of survey respondents reported some difficulty with staying motivated to work on their STEM courses after they moved online, with $45 \%$ characterizing motivation as a major problem. A majority of STEM students also reported having problems knowing where to get help with the course after it went online, finding a quiet place to work on the course, and fitting the course in with other family or home responsibilities. Major challenges to continuing with the course were more prevalent among women, students identifying as a race/ethnicity group minoritized in STEM, students taking their course at a community college, and those from lower-income households.

Overall, students who reported experiencing a greater number of major challenges with continuing their course after it went online expressed lower levels of satisfaction with their course after COVID-19. An exception to this general pattern, though, was found for students from minoritized race/ethnicity groups, females, and lower-income students. Despite experiencing more challenges than other students did with respect to continuing their STEM courses remotely, these students were more likely to rate the quality of their experiences when their STEM course was online as just as good as, or even better than, when the course was meeting in person.

Only $14 \%$ of students taking STEM courses were very satisfied with how well they were learning in their course after it moved online. But most students did not attribute their dissatisfaction with aspects of their STEM courses after COVID with poor instructor preparation or limitations inherent in online learning. Moreover, online STEM courses that used a larger array of recommended online teaching 
practices had higher student satisfaction levels than those that used fewer of them. The practices most closely associated with greater course satisfaction were sending personal messages to students about how they were doing in the course, using real-world examples to illustrate course content, and assignments calling for reflection on the state of one's learning. 
Side-by-side photographs of two young women illustrate Nicholas Casey's April 4, 2020 New York Times article "College Made Them Feel Equal. The Virus Exposed How Unequal Their Lives Are." On the left pale colors of beige and gray predominate as Isabel Caning stands in front of her family's vacation home in Maine. On the right, we see the bright colors and painted palm trees on the food truck operated by the family of her classmate Tatiana Lathion. Both college seniors had played on the same lacrosse team, lived in the same college dorm, and were recruited to be undergraduate teaching assistants for the same course at Haverford College. When Haverford closed its campus for the coronavirus, Caning carpooled to the family home in Maine where she could continue her studies in a quiet place; Lathion went to Florida where she had to turn her attention to helping her parents find and prepare food to keep the family business afloat. Anita Isaacs, professor for the course for which both students assisted, summed up the change in perspective after COVID-19, "It's as though you had a front-row view on American inequality and the ways in which it was disguised and papered over."

\section{Background}

The hasty shift to delivering college courses through remote instruction in spring 2020 was difficult for both faculty and students. Faculty had to shift their courses online in a matter of days, and many were called upon to use technologies they had never worked with before. Students had to figure out where they would live, how they would support themselves, and how they could connect to their courses, all while missing the interaction and support of their peers and instructors. Experts in online teaching practices point out that the spring 2020 course experiences should not be construed as representative of online learning as it occurs in a course designed for this modality and delivered by instructors trained to teach this way (Hodges et al., 2020; O'Keefe, Rafferty et al., 2020). Nevertheless, as higher education institutions, faculty, and students look forward to fall 2020 and beyond, the "COVID experience" has much to teach us about barriers to student participation in online course activities and student perceptions of online instruction. We should not lose the opportunity to extract insights from this experience, which revealed the magnitude of underlying equity gaps as well as strengths and weaknesses in higher education's preparation for delivering instruction online at scale. Gathering and synthesizing these lessons can inform future practice, not only in online courses but also in courses combining elements of digital and in-person instruction.

\section{Survey Sample and Method}

Digital Promise and Langer Research Associates (https://langerresearch.com) developed the Survey of Student Perceptions of Remote Teaching and Learning to capture the experiences of undergraduates taking courses that transitioned to online instruction in response to the COVID pandemic. The survey explores the nature of college courses as they were taught after the COVID-19 outbreak, the pervasiveness of various challenges undergraduates faced after the transition to remote instruction, and course features associated with higher levels of student satisfaction. Data analyses compared experiences of students from low-income, under-represented race/ethnicity and gender groups, or rural backgrounds to those of students without these characteristics. 


\section{A word on terms used in this report...}

\section{Inequality versus inequity}

The choice of the term "inequality" for the title of this report was intentional and reflects the distinction between the terms "equality" and "equity" as we now understand them. Equality is about giving everyone the same thing or treating everyone in the same way. Equity refers to a standard of moral or ethical fairness that takes into account the fact that the exact same treatment or portion may not be enough to support full participation by every individual. Giving equal resources to everyone can result in inequity because those resources can be insufficient for some students to thrive (for example, English learners or those with a visual impairment may not be able to profit from the print textbook their classmates are using). Education systems have been undergoing self-examination with respect to inequities built into their business-as-usual practices. During the COVID-19 pandemic, however, many colleges struggled to provide all their students with even the basics of equal access to instruction. The loss of campus internet and computers meant that some students had what they needed to continue with their coursework while others did not - hence, inequality.

\section{Online versus remote learning}

Under normal circumstances, online courses are designed for delivery over the internet, and the faculty and students participating in them have chosen this modality. What happened during the spring of 2020 was a hasty and unanticipated shift of courses using face-to-face instruction to delivery online. Those with extensive experience designing and delivering online courses cautioned researchers and education critics against viewing the COVID experience as a test of online learning and suggested using other terms, such as "emergency remote teaching," to describe what was going on (Hodges et al., 2020; O'Keefe et al., 2020). While acknowledging the validity of this point, we used the term "online learning" in the student survey because of its greater familiarity to students. We have carried through with use of the term "online" in this report to correspond to wording of the survey items. Occasionally, we do use the term "remote" here, but without intending any distinction from the instruction elsewhere labeled "online."

\section{What kind of students?}

We recognize that the way individuals and groups of individuals are described is important, and that labels that government data collections and research publications have used in the past are increasingly viewed as problematic in lumping very disparate groups together (for example, describing people of Chinese, Filipino, and Hmong descent all as "Asian"), bear connotations about what is normal or standard (implicit in terms like "subgroup," "non-White," or "low-income"), and highlight one characteristic of an individual while ignoring others. At the same time, our research sought to capture the STEM learning experiences of different kinds of students in order to address equity issues, and our options for describing students were limited by the way in which background information was collected for the survey panel (e.g., using federal Community Population Survey items for race and ethnicity) and by the requirement to have large enough numbers of students with a common characteristic to produce a reliable estimate of the group's response. For this latter reason, we can report reliable survey findings for only two race/ethnicity groups (Hispanic and non-Hispanic White). We did not have a large enough sample of Asian students to support reporting for that group by itself (yet alone for its constituent groups of Asian ethnicities), nor was there an adequately large sample of Black students taking STEM courses. To use survey responses from the entire sample and be able to examine differences in course experiences associated with race/ethnicity group, we created two large categories--one consisting of students who described themselves as Black, Hispanic, Native American or Alaskan Native, Pacific Islander, or a combination of backgrounds including one or more of these, and one of students who described themselves as non-Hispanic White or Asian or a combination of backgrounds involving these two. These two broad categories are admittedly coarse, but they do capture the divide between those race/ethnicity groups that are found in STEM majors and careers at rates lower than their prevalence in the U.S. population and those that participate in STEM at rates equal to or greater than their population prevalence. We refer to these groups as "minoritized in STEM" and "non-minoritized in STEM" while acknowledging that Asian students, included in our nonminoritized group for purposes of discussing STEM education, are minoritized in other contexts. 
This survey was administered to a random national sample of 1,008 undergraduates, age 18 and older, who were taking college courses for credit that included in-person class sessions when the COVID pandemic hit and had to finish the course by learning at a distance. Respondents had the option to take the survey in Spanish or English. The survey asked respondents to choose one of their STEM courses that had shifted online to describe in answering survey items. Students who were taking more than one STEM course were asked to respond for the STEM course they thought was most important for their future. Students who were not taking any STEM courses were asked to respond for the non-STEM course they considered most important for their future.

Sixty-two percent of the national survey sample of 1,008 had been taking one or more STEM courses with in-class meetings that had to go online during the COVID-19 pandemic, and this report describes their responses. Forty-two percent of the sample described themselves as majoring in a STEM field.

Survey results have a sampling error of 3.6 percentage points for the full sample and 4.6 points among students who took a STEM course.

Data were collected May 13 to June 1, 2020, with sampling and data collection by Ipsos Public Affairs via its online, probability-based KnowledgePane ${ }^{\circledR}$, which provides Internet survey access to randomly recruited participants. Survey findings for the entire sample of 1,008 students are reported elsewhere (https://www.everylearnereverywhere.org/resources/suddenly-online-national-undergraduatesurvey/l.

A fuller description of the survey methodology and sample weighting appears in Appendix A. Appendix B contains responses to each survey item from students taking STEM courses.

\section{Findings}

Who were the students taking STEM courses in 2020 before the COVID-19 pandemic?

Participants in the Ipsos Knowledge Panel complete an extensive personal profile when they join the panel. This procedure enabled us to examine characteristics of undergraduates enrolled in STEM courses and to contrast them with those of students who were not taking any STEM courses without having to ask what some might have construed as intrusive questions on our survey.

Gender. When asked to complete a survey, females are consistently more likely than males to participate (Curtin et al., 2000; Moore \& Tarnai, 2002), and that was the case with our undergraduate survey as well. Before applying sampling weights, $64 \%$ of survey respondents were female (compared to $54 \%$ of all undergraduates according to the American Community Survey). Population weights based on the American Community Survey were applied to obtain nationally representative data from the survey sample. After sampling weights were applied, larger proportions of male (67\%) than of female (60\%) survey respondents were taking one or more STEM courses with in-person meetings before all classes went remote in spring 2020.

Next we examined the gender break down of the 620 students within the sample of 1,008 who were taking one or more STEM courses in spring 2020. The greater proportion of females in the 
undergraduate population and the greater propensity of males to take STEM courses counterbalanced each other: Our weighted survey sample of STEM coursetakers was $50 \%$ male and $50 \%$ female.

Race/Ethnicity. Of non-Hispanic White students responding to the survey, $66 \%$ said they were taking a STEM course as were $61 \%$ of Hispanic students and $54 \%$ of Black students. The weighted sample of survey respondents taking STEM courses was $54 \%$ non-Hispanic White, $22 \%$ Hispanic, and $12 \%$ Black, with the remainder comprised of Asian and other race/ethnicity groups. Only the Hispanic and nonHispanic White subgroups were large enough to generate precise statistical estimates. At 55 , the unweighted sample size for Black students is too small to provide reliable estimates for this group by itself. For purposes of statistical testing of differences related to race and ethnicity, two broader student groups were formed: Students from minoritized race/ethnicity groups under-represented in STEM (consisting of Black, Hispanic, Alaska Native or Native American students and respondents who described themselves as mixtures of these backgrounds) constituted $36 \%$ of the STEM survey sample, with students from groups better-represented in STEM (consisting of non-Hispanic Whites and Asians) comprising $64 \%$.

Age. Students taking STEM courses spanned a wide age range. Forty percent were under age $21 ; 26 \%$ were 21 or 22 years old; $13 \%$ were age $23-25$; and $20 \%$ were age 26 or older.

Income Level. Less than a third (28\%) of the students in the STEM survey sample came from households with annual incomes of less than $\$ 50,000 ; 30 \%$ from households with incomes between $\$ 50,000$ and $\$ 100,000$; and $42 \%$ from households with annual incomes of $\$ 100,000$ or more. For students who were not taking STEM courses, the comparable figures were $32 \%, 28 \%$, and $40 \%$.

Urbanicity. Among undergraduates who were taking a STEM course, 37\% said they lived in a location that was classified as urban; $52 \%$ in one classified as suburban; and $11 \%$ as rural. The relatively small size of the latter subgroup limits what can be inferred about rural students taking STEM courses based on this survey.

Region. Of respondents taking a STEM course, $37 \%$ said they lived in a location classified as the South; $26 \%$ as the West; $20 \%$ as the Midwest; and $17 \%$ as the Northeast.

Our survey included questions asking students to indicate the subject of the course they were describing on the survey, the kind of higher education institution offering that course, how many online courses they had taken in the past, and whether or not they were majoring in a STEM field.

Type of Institution. More than two-thirds (70\%) of the undergraduates taking STEM courses were taking them in four-year colleges. Students from minoritized race/ethnicity groups were more likely than nonHispanic White students to be taking their STEM courses at two-year colleges: $43 \%$ of students from minoritized race/ethnicity groups were taking their STEM course at a two-year college compared to $21 \%$ of students from non-minoritized groups. More specifically, $45 \%$ of Hispanic students and $39 \%$ of Black students in the survey were taking their STEM course at a community college. Community college attendance was also more prevalent among students age 26 or older, students from urban or suburban households compared to those from rural homes, and students from Western states compared to those from other geographic regions. Students from higher-income households (with annual incomes of 
$\$ 100,000$ or more) were less likely than those from less affluent homes to be taking their STEM courses at two-year colleges ( $21 \%$ compared to $35 \%$ ).

Among students attending four-year colleges, $79 \%$ said their institutions were public and $21 \%$ said they were private. (Very few students attending two-year colleges said their institutions were private.)

Course Subject. Of the STEM courses described by students, $17 \%$ were biology courses; $15 \%$ were mathematics courses; $13 \%$ computer science or technology; $12 \%$ engineering or engineering technician; $10 \%$ chemistry; $10 \%$ health professions; and the remainder were courses in other STEM subjects, none of which was described by $10 \%$ or more of the sample. To obtain adequately large subgroups for subsequent analyses, course subjects were clustered into four broad fields: biology; mathematics; computer, information or data science; and other STEM subjects. Students who described a mathematics course were more likely to be taking their course at a two-year college (41\%) than were students describing a STEM course in other STEM subjects (with proportions studying at a two-year college ranging from $23 \%$ for computer science and related subjects to $28 \%$ both for biology and for other STEM subjects).

Major Field. Almost two-thirds (63\%) of students taking STEM courses in spring 2020 said they were majoring in a STEM field; $29 \%$ said they were majoring in a non-STEM field; and the remainder were undecided or said they were taking courses for a program that did not necessitate a major.

Class Size. The STEM courses students described for the survey had fairly small classes. Fifty percent of students reported that their course had fewer than 35 students, $29 \%$ said it had $35-75$, and $21 \%$ said it had more than 75 students. It is likely that some students were describing the enrollment in their section of a course that had a larger total course enrollment.

Prior Online Course Experience. Most of the undergraduates taking STEM courses in spring 2020 had limited prior experience taking a course online. Forty-three percent had never taken a course online before, and $20 \%$ had taken only a single online course. A larger proportion of community college students (45\%) than of students taking their course at four-year colleges (33\%) had taken two or more online courses in the past.

There were some modest differences between the demographic characteristics of students taking STEM courses compared to undergraduates who were not taking STEM courses. The only statistically significant difference between the two groups, however, was that students who were taking STEM courses tended to be more male ( $50 \%$ versus $43 \%)$ than those who were not taking a STEM course.

The remainder of this report describes survey findings for students taking STEM courses and is organized around the study's six primary research questions:

- How did students' experiences with their STEM courses "post-COVID" compare with experiences prior to the move to remote learning?

- What challenges did students experience in learning STEM online?

- Which challenges were more prevalent among low-income, minoritized race/ethnicity group, and rural students compared to other students?

- What was the nature of online learning in STEM courses during the COVID-19 pandemic? 
- What online instruction practices do students perceive as contributing to their engagement and learning?

- To what extent did different types of prior digital learning experiences or other variables mitigate the challenges associated with the transition to remote STEM learning?

\section{How did students' experiences with their STEM courses "post-COVID" compare with experiences prior to the move to remote learning?}

Students were asked about their satisfaction with their STEM course both before and after it moved completely online, with response options of very satisfied, somewhat satisfied, somewhat dissatisfied, and very dissatisfied. As shown in Figure 1, almost half of the students describing STEM courses (47\%) said they were very satisfied with their course before it went fully online. Student satisfaction with their STEM course after it went online was much lower, with only $15 \%$ of students describing themselves as very satisfied with their post-COVID STEM course experience. Another $42 \%$ described themselves as somewhat satisfied with the STEM course they were describing after it went online.

Student satisfaction with their course after it went fully online was lower for students describing STEM courses than for students describing non-STEM courses. Twenty-seven percent of students describing non-STEM courses were very satisfied with their course after it went fully online compared to $15 \%$ of students describing STEM courses. This difference in course satisfaction levels for STEM and non-STEM courses predated the shift to online instruction: Sixty percent of students describing non-STEM courses said they were very satisfied with their course before it went online compared to $47 \%$ of students describing a STEM course.

Nevertheless, the majority of students (57\%) describing STEM courses said they were at least somewhat satisfied with their course after the shift to remote instruction. In summary, while fewer than 1 out of 6 students was clearly happy with their STEM course during COVID, a majority were at least more positive than negative (the aggregate of the very satisfied and somewhat satisfied respondents).

Figure 1. Satisfaction with their course before and after the move to remote instruction

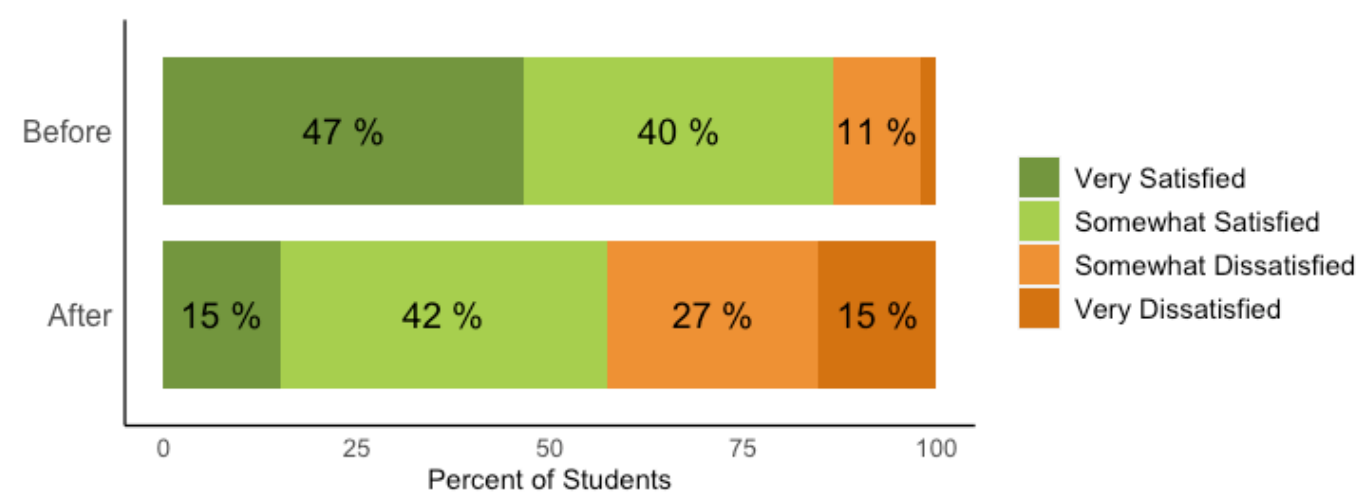


The survey also asked students to rate their satisfaction with multiple dimensions of their course after it went online, as shown in Figure 2. The area in which satisfaction suffered most after COVID was how well students thought they were learning: Only $14 \%$ of respondents said they were very satisfied with how well they were learning post-COVID. In contrast, $23 \%$ of students describing non-STEM courses reported being very satisfied with their learning in their course after it went online, a significant difference.

Figure 2. Student satisfaction with quality of four dimensions of their online course

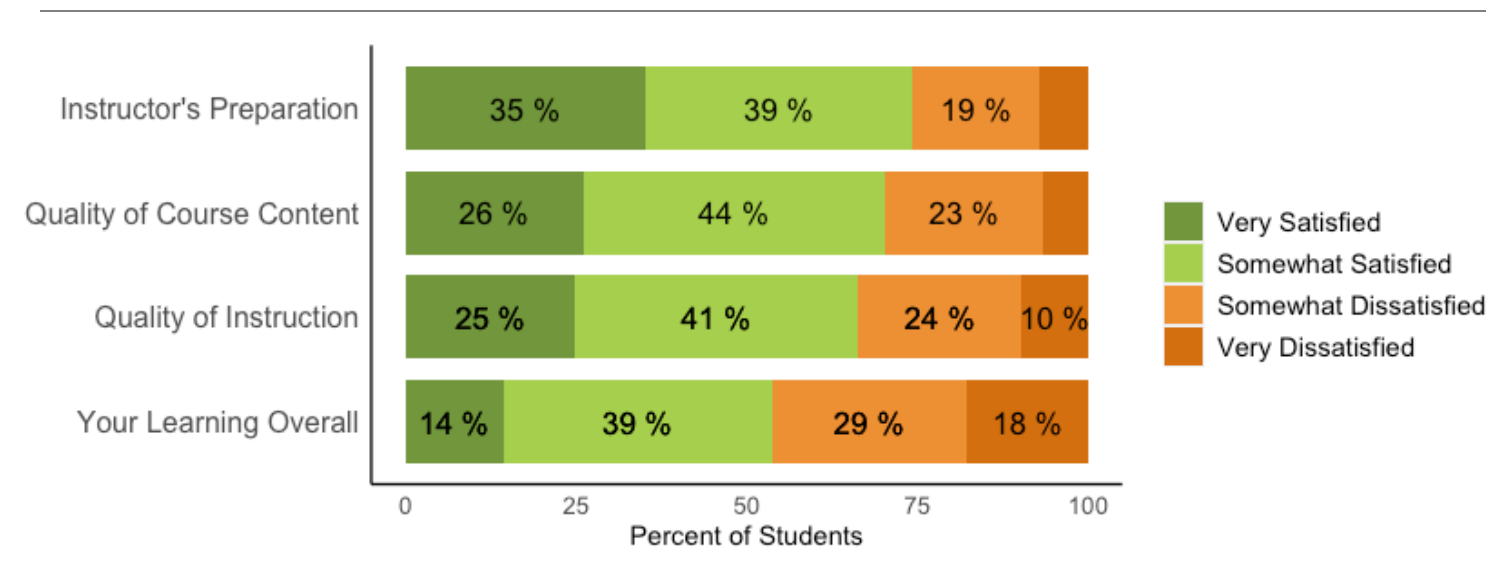

Students were also asked to compare six aspects of their course experience before and after the course went online. These six facets of student course experience were included on the survey because prior research suggests that they relate to student outcomes including course grades, college retention, and persistence in STEM fields (National Academies of Sciences, Engineering, and Medicine, 2019). There is also research evidence that some of these experiences are especially consequential for groups underrepresented in STEM (women in most STEM fields, students from low-income backgrounds, and students with disabilities as well as those from minoritized race/ethnicity groups).

A student's sense of belonging in a course or field of study is associated with college retention and persistence in the field (Strayhorn, 2012). Ample research shows that women and students of color have a lower sense of belonging in STEM courses of study (Good et al., 2012; Johnson, 2012; Smith et al., 2013), with female students of color least likely to feel a sense of belonging in STEM fields other than biology (Rainey et al., 2018). In a related vein, studies of persistence in college STEM programs suggest that some students perceive STEM faculty as unavailable or intimidating, leading to a low level of interaction with faculty, an experience associated with leaving STEM as a field of study (Daempfle, 2004). Peer interactions and strong interpersonal relationships can increase students' sense of belonging (Ramsey et al., 2013; Smith et al., 2013), and students' sense of belonging in STEM is associated with student retention and persistence in the field (National Academies of Sciences, Engineering, and Medicine, 2019; Smith, Lewis, Hawthorne, \& Hodges, 2013; Walton \& Cohen, 2011). Perceptions of instructor responsiveness also appear to be important. Fouad et al. (2010) found that math and science teachers who were quick to help students who needed assistance had students with greater interest in pursuing careers in those fields. Another line of research suggests that instructors can contribute to students' sense of belonging and content mastery by increasing the amount of structure in 
a course and the transparency of their expectations for course assignments (Winkelmes, 2013). This practice appears to be especially helpful for students from minoritized race/ethnicity groups (Eddy \& Hogan, 2013; Winkelmes et al., 2016). Similarly, opportunities to collaborate with fellow students in peer instruction and in project-based learning have been found to enhance learning for all students but appear to have a particularly positive impact for students from minoritized groups (Freeeman et al., 2014). First-year courses that engage students in teams working together on real-world engineering problems, for example, have been found to increase student persistence in engineering (Fortenberry et al., 2007; Lichtenstein et al., 2014). Finally, the research literature has highlighted a mismatch of personal and cultural values held by students from minoritized race/ethnicity groups and those in STEM fields as a factor in limiting diversity in STEM (Eccles, 2009; Stephens et al., 2012). Students who begin STEM majors and then switch out of them often cite a lack of interest in the content (Emekalem, 2019).

For purposes of keeping the student survey brief and easy to interpret, survey items corresponding to students' course experiences related to these constructs were written in simple, everyday language. Transparency around course expectations was operationalized as "understanding what was expected of you in the course," for example. Two aspects of instructor responsiveness were probed: "the instructor's knowledge of your strengths and weaknesses" and "the availability of help with the course content." Sense of belonging in the course was characterized as "your feeling included as a member of the class." The extent to which the course made STEM content interesting was expressed as "keeping you interested in the course content." Opportunities for collaborative learning and forming connections with peers were stated as "opportunities to collaborate with other students on course work." Figure 3 shows students' comparison of these experiences in their STEM courses as taught before and after going completely online.

Figure 3. Comparison of student experiences in their course before and after the shift to remote instruction

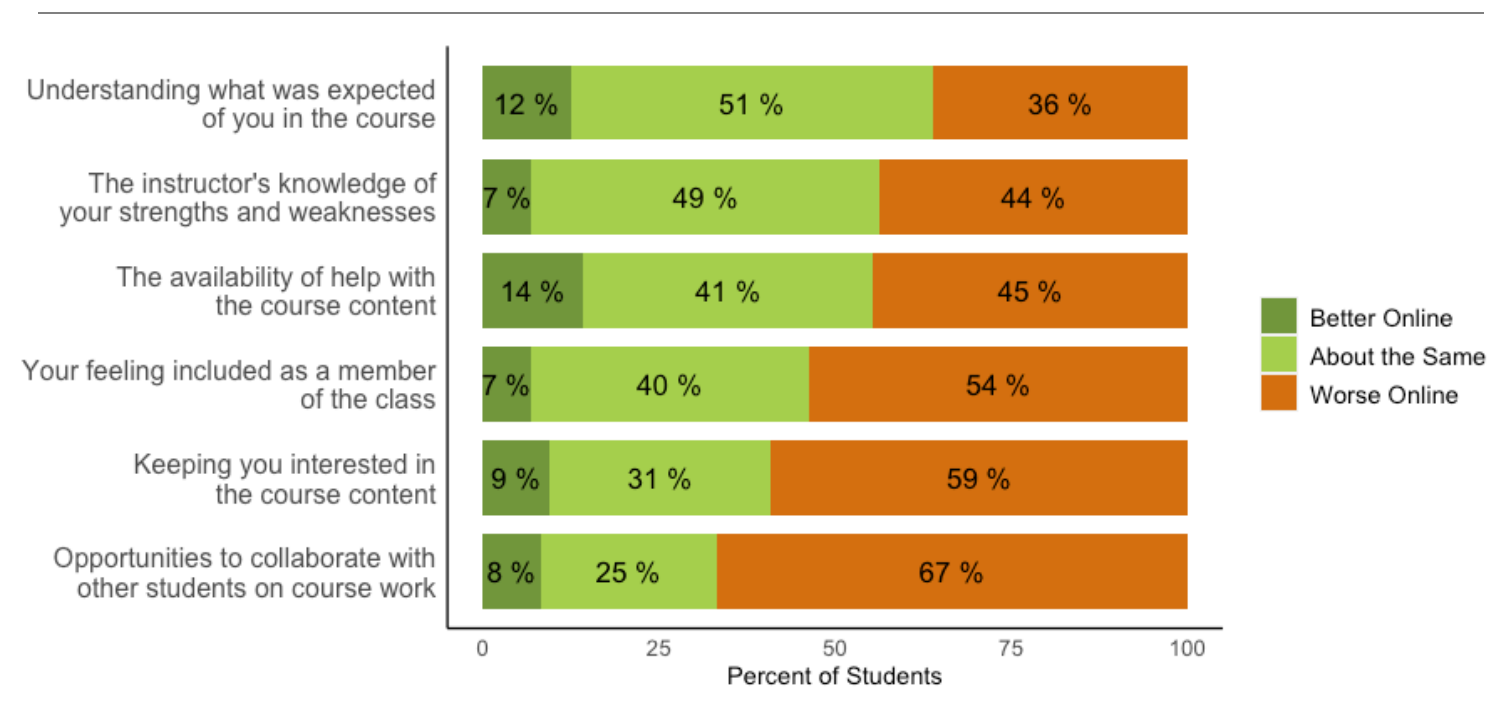


Specific aspects of the course experience that half or more of the students perceived to suffer after moving to remote instruction were:

- Opportunities to collaborate with other students on course work (67\% thought opportunities were worse or much worse online),

- Keeping you interested in the course content (59\% thought worse or much worse online), and

- Your feeling included as a member of the class (54\% thought worse or much worse online).

On the other hand, a majority of students thought the course was about the same, better, or much better after going online in terms of:

- Their understanding of what was expected in the course (64\%),

- The instructor's knowledge of their strengths and weaknesses (56\%), and

- The availability of help with the course (55\%).

Differences among race/ethnicity groups in how remote instruction affected students' course experiences are discussed later in this report.

Clearly most students were less happy with their STEM course after it moved online. Importantly, though, several aspects of the data suggest that most students did not lay the blame for the deterioration of their course experience on their instructors or on inherent limitations of the online modality. As shown in Figure 2, their instructor's preparation for teaching their course online was the dimension of their course students were least likely to rate negatively. Asked about change over time during the period of online instruction, $29 \%$ of students said their instructor's online teaching skills got better over time during the COVID pandemic compared to $16 \%$ who thought it deteriorated over time. In response to another survey item that asked respondents to choose between the unplanned move to online instruction and inherent limitations of online learning as the source of problems with their course as it was implemented post-COVID, more students attributed problems to the former ( $48 \%$ compared to $39 \%$ ) with $13 \%$ saying they didn't experience any problems with the course after it moved online.

\section{What challenges did students experience in learning STEM online?}

The survey included an open-ended item asking students to describe the biggest challenge they experienced in continuing their STEM course after it moved entirely online.

Many student responses to this open-ended question focused on staying motivated when they did not have the structure of regular class routines.

Staying on top of the work was hard for me. If I was in my bed it was hard to get up and do the work before the deadline. - Black female student at a public four-year institution

Mustering the motivation to watch recorded lectures. Often my professors would assign lectures that were longer than the assigned duration of the class, and lectures were not made available at the proper times. Online classes felt much more like work than they ever did on campus.- White male student at a public four-year institution

Discipline to get things done was the hardest to overcome during this time. - Black male student at a public four-year institution 
Many students described distractions or stresses in their home environments as contributors to this lack of motivation to work on their course.

Being a mother to four children I had no away time from them until late at night. It is just very difficult to work from a computer for each class when having small children. - Hispanic female student at a private four-year institution

I think it was harder to feel like the content was worth spending time on. Having the entire internet in front of me can be incredibly distracting and it makes doing the work seem less appealing. It was also much easier to be able to use other mediums to learn the material, making it seem a bit more unnecessary.-Black female student at a public four-year institution

Vivir en un hogar latino, donde primero son los quehaceres antes que la escuela. [Living in a Latino home, where chores come first before school.] - Hispanic female student at a public four-year institution

A related issue cited by many students was time management, another area in which loss of their regular routine added to the challenge.

Time management. Because I didn't have live online classes and then I could listen to lectures whenever, so I was unmotivated to listen to the lectures on my own time. - Other race female student at a public four-year institution

Trying to stay focused and on top of things without having the same daily schedule and regular inperson chats. It was a lot easier to get left behind and for once in my academic career, I actually got behind a lot on work. - White male student at a public four-year institution

Another theme found in many of the open-ended responses was loss of social engagement. Students reported missing the presence of their instructor and peers while they learned. Student responses such as those below suggested that there was an affective component to this challenge, with students expressing nostalgia for lost connection and closeness.

Because of the separation from the professor, I had a hard time keeping motivated because the class wasn't designed for online learning. - White male student at a private four-year institution

Losing the ability to ask classmates for help and having group study sessions. - Hispanic female student at a public four-year institution

Not being able to get into contact with the professor as easily as being in person and knocking on their office door. - White male student at a private four-year institution

Other students writing about lost engagement pointed to more cognitive aspects, highlighting loss of the opportunity to get immediate feedback from their instructor concerning their understanding or performance and of missing the chance to deepen their understanding by discussing course content with peers.

Math is difficult to piece together solo, especially higher-level math. While the instructor lays out the steps very well, it isn't possible to ask questions immediately since the lectures are pre-recorded 
video. There's a delay, and it doesn't help as effectively as immediate response. - White female student at a public four-year institution

Not being able to ask questions at the time they form and having to wait before getting clarification on confusing segments. - Hispanic male student at a public four-year institution

If I missed a step in a math problem I couldn't get answers right away. I'd have to send an email and wait. - Hispanic female student at a two-year college

During in person lectures I was able to ask my peers and my teacher for help with something I was struggling with and they would be able to show me how to do it. When class went online I was no longer able to ask for help the same way I could before, and it was harder to teach myself the class. White female student at a public four-year institution

Many STEM students also highlighted the loss of authentic hands-on experiences that were important to developing understanding or for the particular subject they were studying.

There was not a good way to get help while working on any of the lab portions. Hard to know if you were doing things correctly with proper outcomes. - White male student at a public four-year institution

Organic chemistry lab was much harder because you were writing a lab report on an experiment you obviously didn't do physically - White female student at a public four-year institution

My clinical in-hospital experiences were moved to online. It was very hard to get anything out of it. I could not spend face to face time with patients or actually doing the work. - White female student at a two-year college

Some of the students' descriptions of their challenges suggested frustration with their instructors' teaching techniques, lack of effort, or unfamiliarity with the online teaching tools they were using.

Asking questions was much harder because the professor struggled with the application and frequently missed student questions and concerns. - Multi-racial female student at a public four-year institution

[My] instructor would sometimes put on a video [for us] to learn and then walk away without realizing that he had turned off the sound so we couldn't hear it. He'd come back an hour later and then ask how it went. We tried to ping him to tell him the audio was off but he didn't give us a way to reach him so we watched it silently so it didn't get counted as we were absent but we got nothing out of the video. - Hispanic male student at a public four-year institution

The teacher's inflexibility in group projects once the class went online and the lack of instruction on how to use new technologies such as Zoom, Google Slides, etc. It was expected for all students to use these technologies but no information was given for how to use them to their full capacity. It was more self-taught not only with the course but also with the technology needed to access and participate within the course.. - Black female student at a public four-year institution 
In response to this question about their greatest challenge, a small proportion of students answered by saying they had adapted very well when the course moved online.

None. I did very well in my courses. - Black female student at a public four-year institution

I didn't feel like I had any challenges specific to the "online" aspect of the course. The greatest challenge was probably just that the course content was difficult. - Other race female student at a private four-year institution

All in all it's a great learning experience. We have all had to come out of our comfort zone and go with the flow. If we work real hard we can step out of the box and rise to the occasion. It's not always easy but we have to try and our professors work with us and for most of us were all doing well. What can I say this is real life and we all are having to adapt. - White female student at a public four-year institution

The survey also included structured-response items asking students to rate their experiences with a specific set of problems they may have faced in trying to continue with their courses after COVID. Consistent with responses to the open-ended question, the single problem reported by the largest proportion of students was staying motivated to do well in the course after it went online: $82 \%$ of STEM students cited this as a problem ( $45 \%$ said it was a "major problem" for them, and another $37 \%$ said it was a "minor problem"). As shown in Figure 4, other problems were less prevalent than motivation issues but still considered at least a minor problem for a substantial portion of students taking STEM courses. Not knowing where to go for help with the course was cited by $59 \%$ of students; finding a quiet place to work on the course online and fitting the course in with family/home responsibilities were both cited by $56 \%$; feeling too unwell to participate by $46 \%$; and fitting the course in with a work schedule by $31 \%$.

Figure 4. Severity of various problems with online course participation

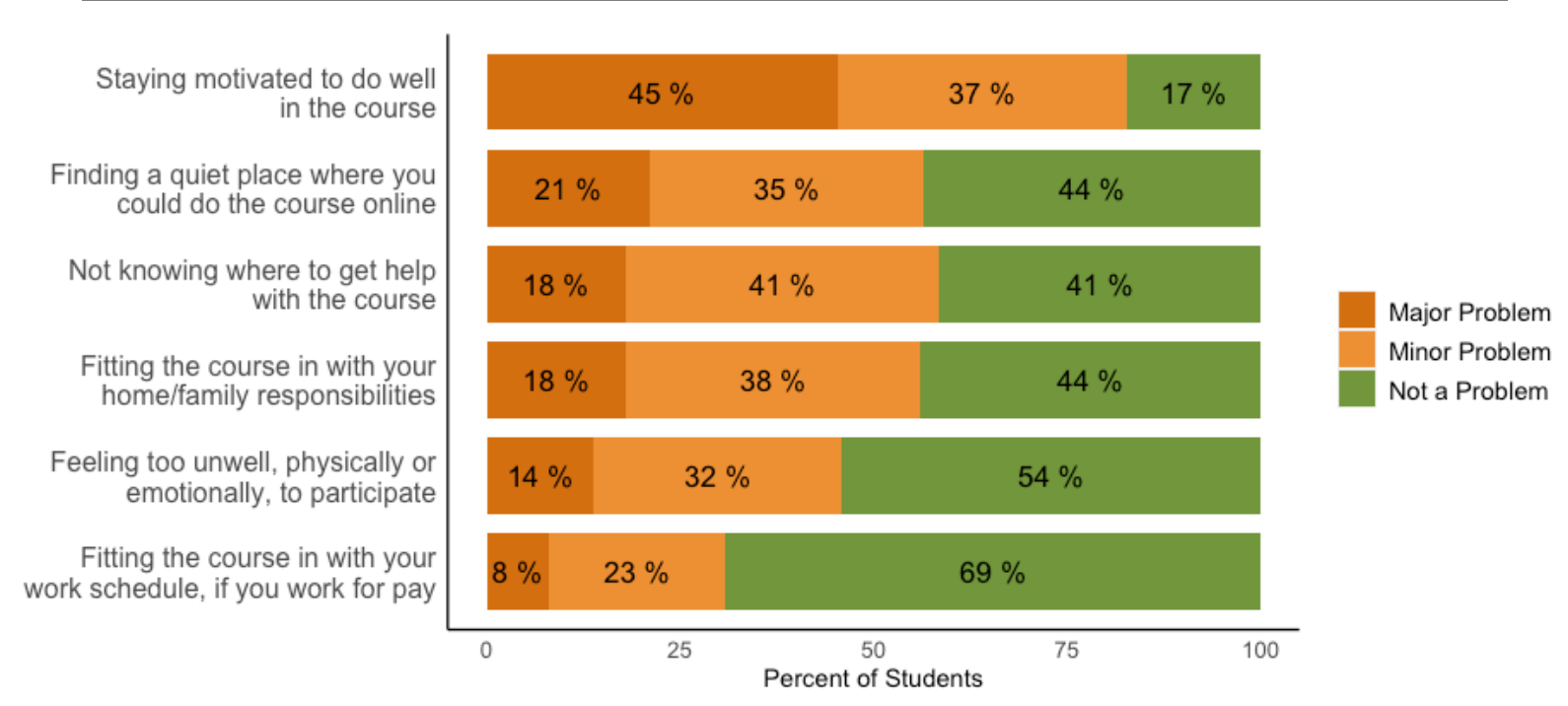


Internet connectivity. Internet access they already had at home was the way the great majority of students (96\%) accessed their STEM courses after COVID. Internet access at their school or near their home at another place arranged by their school was used by just $2 \%$ of students. Another $1 \%$ relied on Internet access in another public place for their course.

Not all internet access is sufficient for digital learning activities, however. Videoconferencing, which was used in many courses, requires high bandwidth, for example. And even high-bandwidth connections can become slow and unreliable when multiple people in the same household are using them at the same time. Internet connectivity issues were serious enough to interfere with students' ability to attend or participate in their STEM course at least occasionally for $46 \%$ of students, with $15 \%$ of students experiencing such problems often or very often.

Poor internet connection made it difficult to submit tests and quizzes in a timely manner, and the live lecture would frequently buffer. - White female student at a public four-year institution

Living on the reservation, no wifi, little help and understanding from instructors. - Other race female student at a public four-year institution

Making sure my WiFi didn't have disconnections especially during bad weather so I could submit my assignments in a timely matter. - Hispanic male student at a two-year college

Device adequacy. Four out of five of students (80\%) used a laptop computer to access their course after COVID. A desktop computer was used by $16 \%$, a tablet by $3 \%$, and a smartphone (which some have argued is inadequate for full participation in academic learning; see, for example, Anderson \& Kumar, 2019; Hampton et al., 2020) by $2 \%$. The great majority of students in STEM courses (92\%) were the sole users of the device through which they accessed the course, but $7 \%$ had to share their device with others (a lower proportion than the $14 \%$ found for respondents in non-STEM courses). A number of colleges and universities were active in distributing computing devices to students who did not have them this spring (Achieving the Dream, 2020; Flaherty, 2020), and $4 \%$ of survey respondents taking STEM courses said they were accessing their course through a device provided by their college. Another $4 \%$ of respondents said the device they used was owned by someone other than themselves or their college.

Almost a quarter of students taking STEM courses (23\%) reported experiencing hardware or software problems serious enough to impact their ability to attend or participate in their STEM course at least occasionally with $7 \%$ reporting that they had such problems often or very often.

Hardware and software problems tended to be experienced by the same students who had difficulties with their internet connection. About one in six students taking a STEM course had both hardware/ software problems and internet connectivity problems often or very often.

Students who experienced a greater number of challenges with continuing their course after it went online also expressed lower levels of satisfaction with their course after COVID-19. We created an eightpoint challenge scale by assigning a 1 for every one of the six challenges in Figure 4 that a student cited as a major problem plus a point each for having connectivity or software/hardware problems often or very often. Table 1 shows course satisfaction levels by the number of challenges a student experienced. 
Table 1. Student satisfaction with course overall and with how well they were learning by number of challenges experienced.

\begin{tabular}{|l|c|c|c|c|}
\hline \multirow{2}{*}{ Outcome/Rating } & \multicolumn{4}{|c|}{ Number of Challenges Experienced as Major } \\
\cline { 2 - 5 } & $\mathbf{0}$ & $\mathbf{1}$ & $\mathbf{2 - 3}$ & $\mathbf{4 - 8}$ \\
\hline Course overall & & & & \\
\hline Very satisfied & $27 \%$ & $8 \%$ & $9 \%$ & $7 \%$ \\
\hline Somewhat satisfied & $53 \%$ & $46 \%$ & $34 \%$ & $17 \%$ \\
\hline Somewhat dissatisfied & $14 \%$ & $35 \%$ & $34 \%$ & $38 \%$ \\
\hline Very dissatisfied & $6 \%$ & $12 \%$ & $23 \%$ & $38 \%$ \\
\hline How well you were learning & & & & \\
\hline Very satisfied & $25 \%$ & $6 \%$ & $11 \%$ & $7 \%$ \\
\hline Somewhat satisfied & $52 \%$ & $43 \%$ & $28 \%$ & $15 \%$ \\
\hline Somewhat dissatisfied & $19 \%$ & $40 \%$ & $32 \%$ & $26 \%$ \\
\hline Very dissatisfied & $4 \%$ & $11 \%$ & $29 \%$ & $52 \%$ \\
\hline
\end{tabular}

Students reporting higher numbers of challenges with learning online were less likely to describe themselves as very satisfied and more likely to describe themselves as very dissatisfied with their STEM course post-COVID. Among students who did not report any major problems or technology issues, $25 \%$ described themselves as very satisfied and $4 \%$ as very dissatisfied with how well they were learning in their course after it went online. In contrast, among students reporting four or more challenges, only $7 \%$ described themselves as very satisfied and $52 \%$ described themselves as very dissatisfied with how well they were learning.

Having difficulty maintaining motivation to do well in the course, not knowing where to find help with the course, and feeling too unwell physically or emotionally to participate were the specific challenges most closely related to overall course dissatisfaction. The proportion of students very satisfied with their post-COVID course was only $4 \%$ among those who cited motivation as a major problem compared to $36 \%$ among those who said motivation was not a problem for them. The corresponding satisfaction rates were $4 \%$ for those who said they had a major problem finding where to get course help online compared to $24 \%$ among those who didn't see this as a problem and $7 \%$ for those feeling too unwell to participate compared to $21 \%$ among those not having a wellness problem.

Similar relationships were found between the number of challenges a student experienced and how well the student felt he or she was learning in the course, also shown in Table 1.

Variability in the Experience of Challenges. The proportion of students reporting four or more major problems or challenges in trying to continue their course online was very similar for students taking their courses at two- and at four-year institutions ( $10 \%$ for the former and $12 \%$ for the latter). The proportion of students experiencing four or more challenges did vary, however, by a number of demographic variables as shown in Table 2 below. The proportion of women reporting four or more major problems was more than twice that of the proportion of men (17\% versus $7 \%)$. Part of the explanation for the gender difference may relate to childcare responsibilities: Women were more likely to be responsible for taking care of a child during the COVID pandemic, and those taking care of a child were more likely to 
experience four or more challenges ( $18 \%$ compared to $13 \%$ for those who either were not living with a child or who were in the same household but not responsible for childcare). Hispanic students were more likely to report having experienced four or more major problems ( $19 \%$ and $16 \%$, respectively) than were non-Hispanic white students (7\%). Students in the lowest of the three annual household income groups (annual income of less than $\$ 50,000$ ) were more likely to report having had four or more major challenges (19\% versus $10 \%$ for students in the middle-income group and $8 \%$ of those in the highestincome group). Students who had taken four or more online courses previously were less likely to report having four or more problems with their STEM course post-COVID (only 7\% did so).

Table 2. Number of major challenges experienced in continuing their STEM course online, by student group

\begin{tabular}{|l|c|c|c|}
\hline \multirow{2}{*}{ Student Characteristic } & \multicolumn{3}{|c|}{ Number of Major Challenges } \\
\cline { 2 - 4 } & $\begin{array}{c}\mathbf{0 - 1} \\
\text { Challenge }\end{array}$ & $\begin{array}{c}\mathbf{2 - 3} \\
\text { Challenges }\end{array}$ & $\begin{array}{c}\mathbf{4} \text { or more } \\
\text { Challenges }\end{array}$ \\
\hline Course at two-year college & $62 \%$ & $28 \%$ & $10 \%$ \\
\hline Course at four-year college & $64 \%$ & $24 \%$ & $12 \%$ \\
\hline Male & $72 \%$ & $22 \%$ & $7 \%$ \\
\hline Female & $55 \%$ & $28 \%$ & $17 \%$ \\
\hline Non-Hispanic White & $67 \%$ & $26 \%$ & $7 \%$ \\
\hline Hispanic & $58 \%$ & $23 \%$ & $19 \%$ \\
\hline Lower-income household & $53 \%$ & $28 \%$ & $19 \%$ \\
\hline Mid-income household & $64 \%$ & $26 \%$ & $10 \%$ \\
\hline Upper-income household & $70 \%$ & $22 \%$ & $8 \%$ \\
\hline Responsible for childcare & $51 \%$ & $36 \%$ & $13 \%$ \\
\hline Not responsible for childcare & $65 \%$ & $23 \%$ & $12 \%$ \\
\hline Working 21+ hours a week & $61 \%$ & $22 \%$ & $17 \%$ \\
\hline Working 1-20 hours a week & $60 \%$ & $27 \%$ & $13 \%$ \\
\hline Not working for pay & $66 \%$ & $25 \%$ & $9 \%$ \\
\hline
\end{tabular}

\section{Which challenges were more prevalent among low-income, minoritized race/ethnicity group, and} rural students compared to other students?

Using respondents' self-identifications in terms of race and ethnicity, we categorized students into groups large enough to permit statistical estimation. Here we focus on comparing the experiences of Hispanic students to those of non-Hispanic White students to better understand the disparate impacts of the transition to remote instruction. (There were too few students in other race/ethnicity categories to support reliable statistical estimates.)

Staying motivated to do well in the course, which was the most prevalent challenge for non-Hispanic White students (with $45 \%$ considering it major) was similarly challenging for Hispanic students (44\%). Not being able to find a quiet place to work, the second most widespread challenge overall, was somewhat more common among Hispanic, but did not differ significantly from the frequency among non-Hispanic White students. Twenty-three percent of Hispanic students said finding a quiet place to 
work on the course was a major problem for them, compared to $18 \%$ of non-Hispanic Whites. Larger group differences were found for other challenges. Fitting the course in with home/family responsibilities, for example, was a major problem for $27 \%$ of Hispanic students compared to just $14 \%$ of non-Hispanic White students $(p<.01)$. Feeling too unwell, physically or emotionally, to participate in the course was another challenge more prevalent among Hispanic students: $17 \%$ of Hispanic students reported feeling too unwell to participate as a major problem compared to $11 \%$ of non-Hispanic Whites $(p<.10)$. More Hispanic students (27\%) than non-Hispanic White students $(15 \%)$ reported having a major problem knowing where to get help with the course after it went online $(p<.01)$. These data are summarized in Table 3.

Table 3. Frequency of major problems trying to learn online for selected race/ethnicity groups

\begin{tabular}{|l|c|c|}
\hline Challenge & $\begin{array}{c}\text { Hispanic } \\
(n=135)\end{array}$ & $\begin{array}{c}\text { Non-Hispanic } \\
\text { White } \\
(n=373)\end{array}$ \\
\hline Staying motivated to do well in the course & $44 \%$ & $45 \%$ \\
\hline Not having a quiet place to work on the course & $23 \%$ & $18 \%$ \\
\hline Not knowing where to get help with the course & $27 \%^{* *}$ & $15 \%$ \\
\hline Conflicts with home/family responsibilities & $27 \%^{* *}$ & $14 \%$ \\
\hline Feeling too unwell to participate & $17 \%^{\wedge}$ & $11 \%$ \\
\hline Conflicts with work schedule & $13 \%$ & $5 \%$ \\
\hline
\end{tabular}

$\wedge$ Differs from non-Hispanic White group at $p<.10$

* Differs from non-Hispanic White group at $p<.05$

** Differs from non-Hispanic White group at $p<.01$

Findings for the two large race/ethnicity categories (minoritized and non-minoritized) are shown in Table 4. The pattern of differences is the same as that shown in Table 3, but with the larger sample sizes more of them reach statistical significance. 
Table 4. Frequency of major problems trying to learn online by race/ethnicity catrgory

\begin{tabular}{|l|c|c|}
\hline Challenge & $\begin{array}{c}\text { Minoritized }^{\text {a }} \\
(n=193)\end{array}$ & $\begin{array}{c}\text { Non-minoritized } \\
(n=402)\end{array}$ \\
\hline Staying motivated to do well in the course & $45 \%$ & $47 \%$ \\
\hline $\begin{array}{l}\text { Not having a quiet place to work on the } \\
\text { course }\end{array}$ & $24 \%$ & $20 \%$ \\
\hline $\begin{array}{l}\text { Not knowing where to get help with the } \\
\text { course }\end{array}$ & $25 \%^{* *}$ & $14 \%$ \\
\hline Conflicts with home/family responsibilities & $25 \%^{* *}$ & $14 \%$ \\
\hline Feeling too unwell to participate & $19 \%^{*}$ & $12 \%$ \\
\hline Conflicts with work schedule & $13 \%^{\wedge}$ & $5 \%$ \\
\hline
\end{tabular}

${ }^{a}$ Includes students who identify as Hispanic, Black, Native American, Alaska Native, Pacific Islander, or multiple groups including Hispanic.

${ }^{\mathrm{b}}$ Includes non-Hispanic White and Asian students.

* Differs from non-minoritized student group at $p<.05$

** Differs from non-Hispanic White group at $p<.01$

$\wedge$ Differs from non-minoritized student group at $p<.10$

In terms of technology access, students from minoritized race/ethnicity groups were more likely to experience internet connectivity problems often or very often $(20 \%)$ compared to students from nonminoritized groups (12\%). Students from lower-income households (annual incomes under $\$ 50,000$ ) were also more likely to experience internet connectivity problems often or very often (22\%) compared to students from households earning $\$ 100,000$ or more (11\%). Surprisingly, students with homes in rural communities were not more likely than those in urban or suburban communities to report experiencing internet connectivity problems often or very often (13\% versus $13 \%$ for urban and $16 \%$ for suburban locations), but the sample of rural students taking STEM courses was relatively small. ${ }^{1}$

Hardware or software issues were less prevalent than internet connectivity problems for the survey respondents overall, but showed a similar pattern of differences among race/ethnicity groups.

Frequency of hardware and software problems was lower for non-Hispanic White students (5\% experiencing them often or very often) compared to Hispanic and Black students ( $11 \%$ combined).

Hardware and software issues varied by household income. Just 4\% of STEM students from high-income households reported having these problems often or very often compared to $10 \%$ of students from lower-income households and $8 \%$ of students from middle-income households (annual income of $\$ 50,000-\$ 100,000)$.

\footnotetext{
${ }^{1}$ For a discussion of the policy implications of these data, see the National Digital Inclusion Alliance report Limiting Broadband Investment to "Rural Only" Discriminates Against Black Americans and other Communities of Color.
} 
Some of the responses of students to the open-ended question about greatest challenges also suggest that lower fluency in English and feelings of shyness or stereotype threat may have differentially affected some students when trying to participate online.

My greatest challenge is trying to formulate a question in email. I sometimes struggle to explain what I am trying to ask via an email. It is easier to speak and explain my mind when I am verbally speaking to someone. - Hispanic female student at a two-year college

Fue mas dificil participar en discussiones con la clase porque no era igual como cuando estabamos en persona. En persona, podemos levantar la mano para pedir decir algo, y podemos quebrarnos en grupos physicamente. En linea, eramos mas timidos en compartir nuestras opinones porque no queriamos interrumpir a otra persona. Tomabamos turnos, y hacia la discussion mas lenta. [It was more difficult to participate in discussions with the class because it was not the same as when we were in person. In person, we can raise our hands to ask to say something, and we can physically break into groups. Online, we were more shy in sharing our opinions because we did not want to interrupt another person. We took turns, making the discussion slower.] - Hispanic female student at a two-year college

Attributes that put students at a disadvantage when trying to continue their course remotely (in terms of the number of challenges they faced) are often intertwined. For example, females, low-income students, and students from minoritized race/ethnicity groups were more likely to have responsibility for caring for a child during the COVID pandemic. Fifteen percent of female STEM students were responsible for childcare compared to $7 \%$ of males, and $20 \%$ of Hispanic students were responsible for childcare compared to $8 \%$ of non-Hispanic White students. Among those STEM students from lowerincome households, $18 \%$ were responsible for taking care of children during this period compared to $10 \%$ of those from middle-income households and just $6 \%$ of those from higher-income households. Similarly, students from minoritized race/ethnicity groups taking STEM courses were more likely than their White classmates to be working 31 or more hours a week during COVID (16\% for Hispanic students compared to $8 \%$ of White students).

\section{What was the nature of online learning in STEM courses during the COVID-19 pandemic?}

Table 5 shows common features of STEM courses offered remotely because of the coronavirus After courses moved to remote instruction post-COVID, 70\% held "live" (synchronous) sessions in which students could ask questions and participate in discussions. Recorded lectures were also common (71\% of courses) as was the use of frequent quizzes and assessments (69\%).

Table 5. Features of Online Courses After COVID

\begin{tabular}{|l|c|}
\hline Course Feature & $\begin{array}{c}\text { Percentage of Students } \\
\text { Reporting }\end{array}$ \\
\hline Recorded lectures & $71 \%$ \\
\hline Live sessions & $70 \%$ \\
\hline Live lectures & $60 \%$ \\
\hline Pre-recorded videos, not of instructor & $56 \%$ \\
\hline
\end{tabular}


Grading. A major change in courses after COVID concerned course grading policies. Many colleges and universities extended the time period for choosing to take a course pass/fail or credit/no credit rather than for a letter grade to very late in the academic term. Some institutions even mandated that all courses use credit/no credit grading out of concern that differences in technology access or ability to participate in course activities would make grading unfair. Of the survey respondents who were taking their STEM course for a grade before COVID ( $92 \%$ of the sample), $61 \%$ reported being given the option of taking it either for a grade or pass/fail after COVID and 33\% reported that they had no option but to continue taking their course for a letter grade after COVID. Seven percent of students reported that their STEM course became mandatory pass/fail after COVID.

While inspired by a concern for being fair to students with limited technology access and other challenges to learning at a distance, the abolition or relaxation of grading policies may have contributed to students' struggle to stay motivated to work on their course. When asked about their greatest challenge, several students made comments linking the grading system to their level of motivation.

\section{What online instruction practices do students perceive as contributing to their engagement and learning?}

The survey asked students whether their course after COVID included each of eight instructional practices chosen because they could be expressed in concrete terms on a survey and are prominent in the higher education practitioner literature (American College and University Educators, n.d.; Darby, 2019; Luskin, 2019; Salcido \& Cole, 2018) as contributors to more effective teaching and learning online:

- Assignments that ask students to express what they have learned and what they still need to learn

- Breaking up class activities into shorter pieces than in an in-person course

- Frequent quizzes or other assessments

- Live sessions in which students can ask questions and participate in discussions

- Meeting in breakout groups during a live class

- Personal messages to individual students about how they are doing in the course or to make sure they can access course materials

- Using real-world examples to illustrate course content

- Work on group projects separately from the course meetings

Students' comments when asked about their greatest challenge learning online underscored the importance of a number of these practices.

Staying engaged/focused during lecture. Especially in a 1.5 hour class, motivation started to decline rapidly around halfway through. - Multi-race female student at a private four-year institution

The videos my professors recorded of themselves giving the lecture was nice because it was actually coming from them instead of a random person on YouTube. - White female student at a public fouryear institution 
Not as engaging as in class instruction. The courses were too focused on teaching the book and not the real life examples. Being able to ask questions during the lessons was also absent as it was prerecorded. - White male student at a public four-year institution

When my genetics course was moved online I no longer had access to campus tutoring, and my professor did not hold office hours for students to ask questions and clarify course content. I was left to try and understand all of the material on my own, which was difficult. - White female student at a two-year college

Nearly complete loss of motivation. Especially in classes that only had recorded lectures. It was worlds more manageable in classes where professors checked in periodically and where we had synchronous learning. But nothing can compare to in-person learning. - White female student at a public four-year institution

Table 6 shows the frequency of each of the recommended instructional practices reported by STEM students overall and by students in various kinds of STEM courses. There were statistically significant differences by subject area in the proportion of students reporting the use of assignments having you reflect on what you had learned $(p<.05)$, live sessions in which students could ask questions $(p<.01)$, meeting in breakout groups during a live class $(p<.01)$, and using real-world examples to illustrate course content $(p<.01)$.

Table 6. Percentage of students reporting each instructional practice, by course subject area

\begin{tabular}{|c|c|c|c|c|c|}
\hline Practice & $\begin{array}{l}\text { All STEM } \\
\text { Subjects }\end{array}$ & Biology & $\begin{array}{l}\text { Computer, } \\
\text { Information } \\
\text { or Data } \\
\text { Science }\end{array}$ & Mathematics & $\begin{array}{l}\text { Other } \\
\text { STEM }^{\text {a }}\end{array}$ \\
\hline $\begin{array}{l}\text { Assignments to express what } \\
\text { they have learned and what } \\
\text { they still need to learn }\end{array}$ & $47 \%$ & $37 \%$ & $44 \%$ & $57 \%$ & $49 \%$ \\
\hline $\begin{array}{l}\text { Breaking up class activities } \\
\text { into shorter pieces }\end{array}$ & $32 \%$ & $29 \%$ & $30 \%$ & $31 \%$ & $35 \%$ \\
\hline $\begin{array}{l}\text { Frequent quizzes or other } \\
\text { assessments }\end{array}$ & $69 \%$ & $73 \%$ & $61 \%$ & $73 \%$ & $69 \%$ \\
\hline $\begin{array}{l}\text { Group projects outside of } \\
\text { class time }\end{array}$ & $33 \%$ & $31 \%$ & $29 \%$ & $29 \%$ & $38 \%$ \\
\hline $\begin{array}{l}\text { Live sessions in which } \\
\text { students could ask questions }\end{array}$ & $70 \%$ & $59 \%$ & $66 \%$ & $71 \%$ & $76 \%$ \\
\hline $\begin{array}{l}\text { Meeting in breakout groups } \\
\text { during a live class }\end{array}$ & $23 \%$ & $25 \%$ & $11 \%$ & $29 \%$ & $27 \%$ \\
\hline $\begin{array}{l}\text { Personal messages to } \\
\text { individual students }\end{array}$ & $50 \%$ & $52 \%$ & $44 \%$ & $61 \%$ & $50 \%$ \\
\hline $\begin{array}{l}\text { Using real-world examples to } \\
\text { illustrate course content }\end{array}$ & $65 \%$ & $68 \%$ & $56 \%$ & $62 \%$ & $70 \%$ \\
\hline
\end{tabular}

a Because none of the other STEM subject areas had more than 30 students, they were grouped together as "Other STEM." 
When the relationship between experiencing each of these practices and a student's satisfaction with the course was examined, we found that instructional practices with the largest effects on students' overall course satisfaction were:

- Personal messages from the instructor on how the student was doing or to make sure they could access course materials. Sixty-four percent of those who received messages of this type were satisfied with the course overall, compared to $50 \%$ of those who did not.

- The instructor's use of real-world examples to illustrate course content. Among students whose instructor did this in the online course, $65 \%$ were satisfied overall, compared to a $42 \%$ satisfaction level among those whose instructor did not use real-world examples.

- Assignments requiring students to express what they had learned and what they still needed to learn. Satisfaction with online courses that included such assignments was $67 \%$ compared to $49 \%$ for courses without this feature.

The number of these practices students said their course included was tabulated for each respondent. The number of these online instructional practices incorporated in the course strongly predicted students' satisfaction with their course after COVID.

Figure 5. Satisfaction with Post-COVID course by number of recommended online practices used in instruction

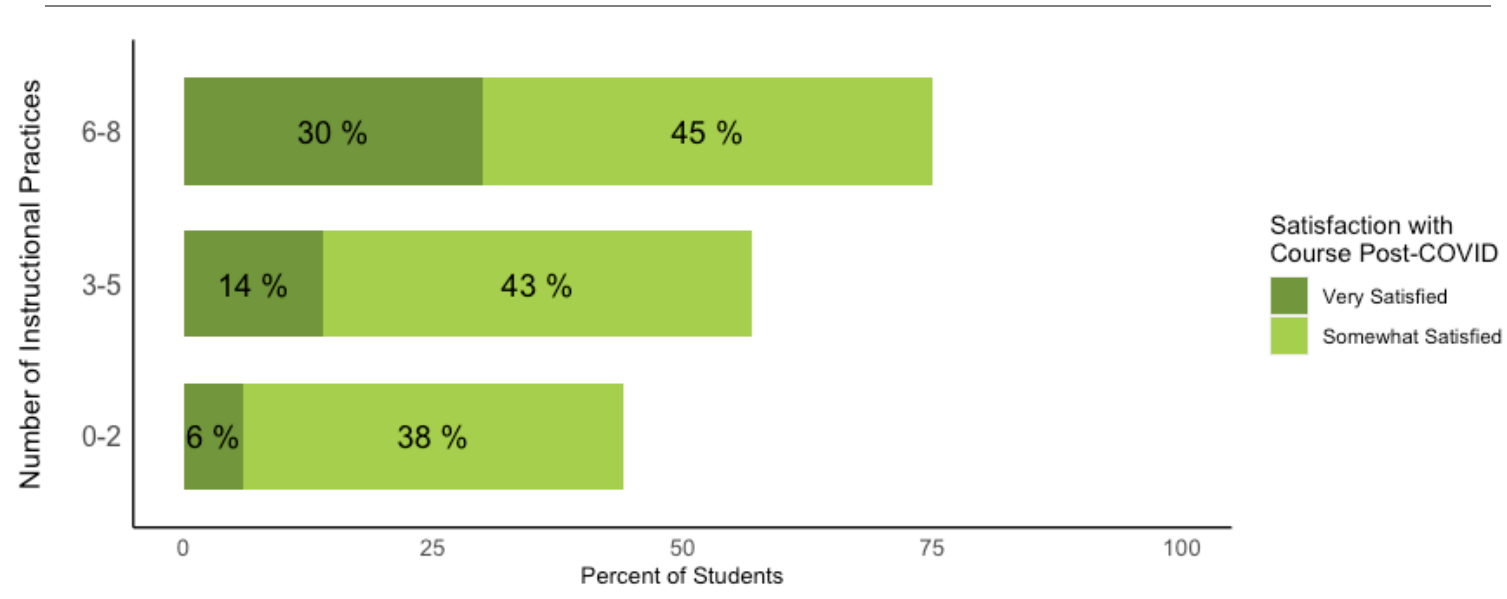

To what extent did different types of prior digital learning experiences or other variables mitigate the challenges associated with the transition to remote STEM learning?

Online courses have become a much more prominent part of education over the past two decades (Tyton Partners \& Babson Research, 2017), but the majority of students taking STEM courses that included in-person classes this spring had limited prior experience with online courses as noted above ( $43 \%$ had not taken any online course before and $20 \%$ had taken only one previous online course). A high level of satisfaction with their course after it moved online was more common among the $37 \%$ of STEM students who had taken two or more online courses in the past: $20 \%$ of them were very satisfied compared to $11 \%$ of those who had taken none, but this differences was not significant statistically. 
A number of other variables also predicted students' level of satisfaction with their course post-COVID. As one would expect, students who were very satisfied with their course before COVID were more likely to be at least somewhat satisfied with it afterward: $66 \%$ of those who were very satisfied before were very or somewhat satisfied after, compared to $61 \%$ of those who were just somewhat satisfied before COVID and 33\% for those who were somewhat dissatisfied or dissatisfied with their course before it went online.

Students' ratings of their satisfaction with their STEM courses before the COVID-19 pandemic were higher for students taking their courses from two-year colleges than for those at four-year institutions (56\% very satisfied before COVID at community colleges compared to $43 \%$ at four-year institutions). The college type satisfaction gap was much smaller and nonsignificant statistically for student ratings of satisfaction with their STEM courses after COVID-19, however (17\% very satisfied in two-year colleges compared to $14 \%$ in four-year institutions). To understand this difference in the "pre/post" rating gap (a pre/post difference of 39 percentage points in two-year colleges compared to one of 29 percentage points for four-year institutions) we explored several possible explanations. Community college students, who were older and more diverse than the students taking STEM courses at four-year institutions, might have experienced a greater number of challenges during the COVID-19 pandemic. Alternatively, community colleges might have been less prepared than four-year colleges to move their courses online.

Neither of these explanations for a bigger change in course satisfaction at community colleges is wellsupported in the data, however. Students attending two-year colleges did not report more major problems than students attending four-year institutions did. Students at the two kinds of institutions did not differ either in terms of likelihood of experiencing frequent internet connectivity or hardware/software problems. One significant difference we did find for students attending the two types of higher education institutions is that those taking STEM courses at a two-year college were much more likely to simultaneously be responsible for the care of a child under 18 ( $20 \%$ for STEM students at two-year colleges compared to $4 \%$ for STEM students at four-year colleges). Students at two-year colleges were also more likely than those at four-year institutions to be working more than 20 hours a week during the pandemic ( $33 \%$ of respondents from two-year colleges compared to $14 \%$ of those from four-year institutions). Weighting each challenge equally in our tally of major problems experienced may have under-estimated the seriousness of stresses associated with providing childcare and working nearly full-time or more while also completing a STEM course online.

In terms of institutional readiness to move their instruction online, several data points suggest parity between two- and four-year institutions from the standpoint of their student "customers." Students at two-year colleges were not less satisfied with their instructor's preparation for online instruction nor were they more likely to say the quality of their learning suffered after the move to remote instruction. Another approach to explaining the larger course satisfaction drop for two-year colleges is to look at the instructional practices employed in courses at the two kinds of institutions. We examined the proportion of courses exhibiting the recommended instructional practices by institution type. As shown in Table 7, most of the statistically significant differences by institution type favor the community college courseswith the prominent exception of assignment of group projects as part of the course after it went online. 
Table 7. Frequency of recommended online instructional practices by institution type.

\begin{tabular}{|l|c|c|}
\hline \multirow{2}{*}{ Practice } & \multicolumn{2}{|c|}{ Institution Type } \\
\cline { 2 - 3 } & $\begin{array}{c}\text { Two-year } \\
\text { colleges }\end{array}$ & $\begin{array}{c}\text { Four-year } \\
\text { colleges }\end{array}$ \\
\hline $\begin{array}{l}\text { Assignments to express what they have learned and } \\
\text { what they still need to learn }\end{array}$ & $55 \%^{*}$ & $43 \%$ \\
\hline Breaking up class activities into shorter pieces & $39 \%^{*}$ & $29 \%$ \\
\hline Frequent quizzes or other assessments & $80 \%^{*}$ & $63 \%$ \\
\hline Group projects outside of class time & $24 \%$ & $37 \% *$ \\
\hline Live sessions in which students could ask questions & $67 \%$ & $72 \%$ \\
\hline Meeting in breakout groups during a live class & $28 \%$ & $22 \%$ \\
\hline Personal messages to individual students & $65 \%^{*}$ & $44 \%$ \\
\hline Using real-world examples to illustrate course content & $66 \%$ & $65 \%$ \\
\hline
\end{tabular}

* Statistically different from the other institution type at $p<.05$.

A companion survey of faculty conducted by Tyton Partners during the same time frame (https://www.everylearnereverywhere.org/resources/time-for-class-covid-19-edition/) reported that a smaller proportion of two-year colleges had a center for teaching and learning or instructional design staff who could help faculty transition their course to the online environment. These supports may have helped faculty at four-year institutions preserve aspects of their courses that students like that were not captured by our survey items.

It should be remembered, though, that students at two-year colleges were not less satisfied than those at four-year colleges with the post-COVID versions of their STEM courses. The difference resided in their higher course satisfaction level pre-COVID, which may well have reflected the value two-year college students place on instructor and peer contact in small classes.

Level of satisfaction with their STEM course after it went online was related to several demographic variables. Female students were more likely than males to be very satisfied ( $18 \%$ versus $12 \%$ ) with the online version of their STEM course $(p<.05)$. There was greater satisfaction with their post-COVID STEM course among minoritized students, but this difference was driven by the responses of Black students ( $14 \%$ of both Hispanic and non-Hispanic White students were very satisfied). Students age 25 or older were more likely than younger students to be very satisfied with their course post-COVID (23\% versus $13 \% ; p<.05)$. These differences will be explored further in the discussion section of this report.

There was also some suggestion that satisfaction with their course post-COVID varied by subject matter: $21 \%$ of students describing a math course said they were very satisfied with their course online compared to $15 \%$ describing a computer or information science course, $13 \%$ for biology courses and $14 \%$ for other STEM subjects, but this difference fell short of statistical significance. Differences in typical class size for these different subjects may account for the apparent subject matter effect, but subject by class size cell sizes were too small to support statistical testing.

White students, students from high-income households, students with more frequent internet connectivity problems, students in large courses, and those who had not taken an online course before 
were more likely than their counterparts to say that their STEM course was worse in terms of two aspects of the course after it went online (feeling included as a member of the class and keeping them interested in the course content).

\section{Discussion}

\section{Inequalities Unmasked}

A puzzling aspect of the survey data for students from minoritized race/ethnicity groups compared to that for students from groups better-represented in STEM is the seeming inconsistency between the data on the challenges experienced trying to continue their STEM courses online and that on students' satisfaction with their course experiences and with how well they were learning. Students from minoritized race/ethnicity groups were more likely to be adversely affected by technical difficulties, conflicts with family and job responsibilities, and feeling too unwell to continue in their course. Hispanic students were more likely than others to report having trouble finding help with their course after it went online. Yet students from minoritized race/ethnicity groups were not less satisfied with their course post-COVID than were students from groups better-represented in STEM. In fact, regression analyses controlling for subject area, class size, and gender found that students from minoritized race/ethnicity groups were more likely than those from race/ethnicity groups better represented in STEM to be very satisfied with the online phase of their course overall (18\% versus $13 \%)$ and with how well they were learning in it ( $17 \%$ versus $13 \%)$.

An examination of race/ethnicity group data for the survey items having students compare different aspects of their course experiences before and after the transition to online instruction may offer the key to unraveling this apparent paradox. As illustrated in Figure 6 below, students from minoritized race/ethnicity groups were less likely than those from non-minoritized groups to judge their post-COVID courses as worse than their course experience before COVID in terms of their feeling included as a member of the class or opportunities to collaborate with other students.

Looked at from this vantage point, these data from the COVID experience are revealing weaknesses of these aspects of minoritized students' STEM course experiences before COVID. The remote instruction during COVID-widely characterized as ill-planned and a poor substitute for the college academic experience-wasn't worse than business as usual for the majority of students from minoritized race/ethnicity groups in many respects. For these students, the experience was as good as, or better than, instruction as usual in terms of their feeling that they belonged in the class, their having clarity about what they were supposed to do in the course, their sense that the instructor knew their specific strengths and weaknesses, and knowing where to get help with the course if they needed it. 
Figure 6. Aspects of their STEM course experience judged equivalent or better online by student race/ethnicity

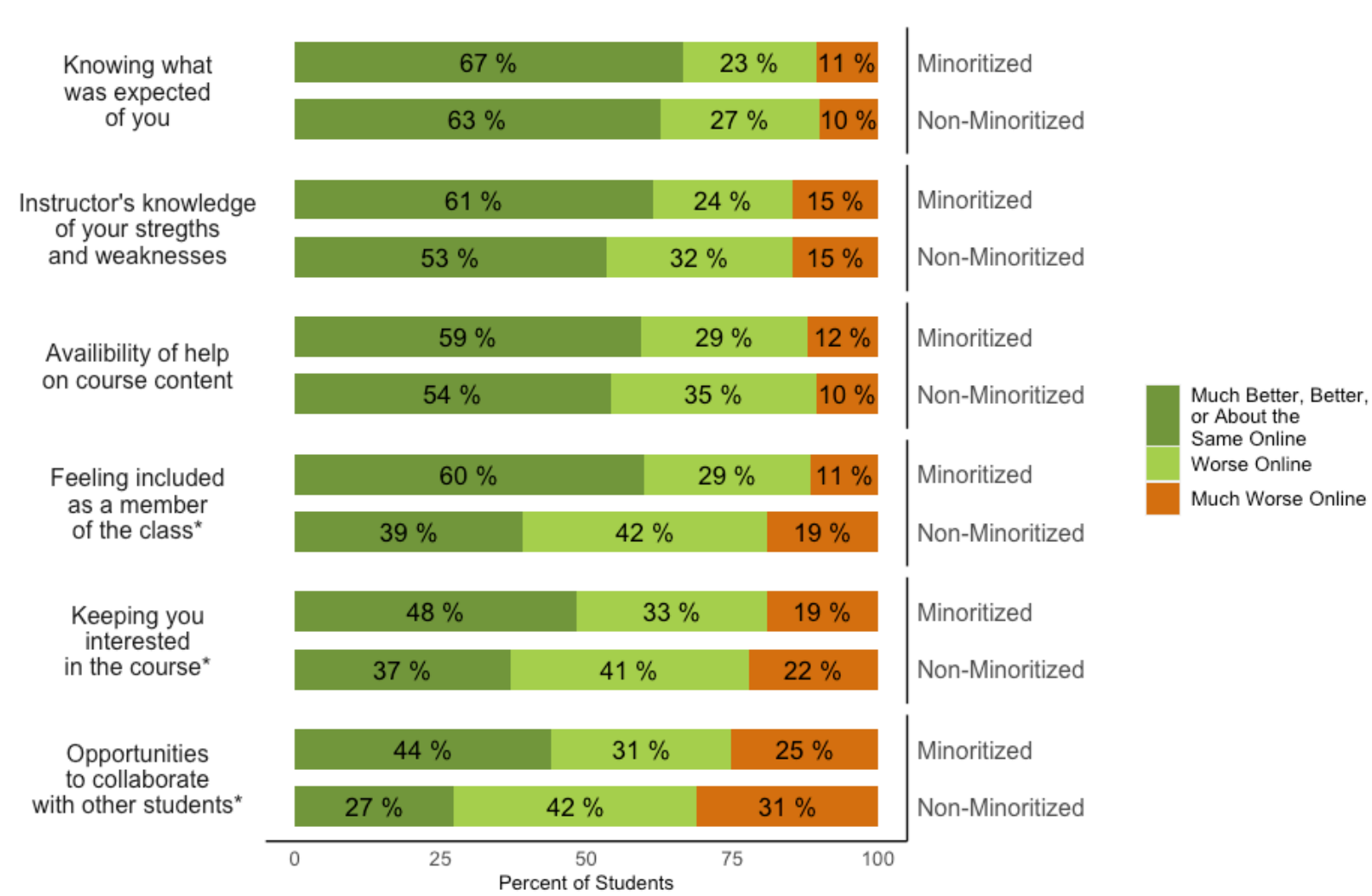

\section{Implications for Future Instruction}

Despite the overall sharp drop in satisfaction with their STEM courses after they went entirely online that students reported, there are some rays of light in the survey data. First, some aspects of courses did not get significantly worse after shifting instruction online. Majorities of students were just as confident they knew what was expected of them in the course, knew where to get help in the course if they needed it, and thought their instructors were as aware of their strengths and weaknesses as they were when the course included face-to-face classes. More importantly, the use of a varied set of online teaching practices recommended in the literature resulted in higher student satisfaction with the course post-COVID. In courses incorporating 6 or more of the recommended online teaching practices, 30\% of students were very satisfied and $46 \%$ somewhat satisfied with their STEM course after COVID. Courses incorporating fewer of the recommended practices had lower satisfaction ratings, as described above. These are practices that can be promoted and modeled in faculty development activities around teaching online.

Of the eight recommended online teaching practices covered in the survey, the three with the most impact on student satisfaction were the inclusion of personal messages to students about how well they were doing in the course (courses including this practice had $23 \%$ of students very satisfied after COVID compared to just $6 \%$ very satisfied for courses without it), course activities that asked students to reflect 
on what they had learned and what they still needed to learn ( $21 \%$ of students in courses with this feature were very satisfied after COVID compared to $9 \%$ in courses without), and use of real-world examples ( $19 \%$ of students in courses with this feature were very satisfied after COVID compared to $7 \%$ in courses without). Moreover, even the most pervasive post-COVID challenge cited by studentsmaintaining motivation to do well in the course-was mitigated significantly by the practice of sending students personalized messages about how they were doing or to make sure they could access course materials ( $59 \%$ of students in courses that did not include personal messages found staying motivated to be a major challenge compared to only $41 \%$ of students in courses that used personal messages). A number of courseware products available for STEM subjects incorporate instructor dashboards identifying students who are struggling and templates for sending appropriate messages to individual students. Activities asking students to reflect on their level of understanding of specific course concepts have also become more common in both digital and nondigital instructional materials.

A recent report from the National Academies of Sciences, Engineering, and Medicine (2018) noted, "a growing body of research suggests that the way introductory courses are taught is a significant factor that discourages students from continuing in STEM" (p. 117). But research suggests also that involving teams of faculty, instructional designers, and faculty development staff in redesigning curriculum and instruction can result in a better course and is also a very effective form of professional learning as faculty gain insights and know-how from each other as well as from their instructional design and faculty development colleagues (Wieman, 2017).

As colleges and universities work with their faculty to deepen their understanding of how to teach in multiple modalities and how to promote active engagement in online classes, a significant portion of the training should focus on developing strategies for dealing with inequities across student populations. In addition to the continuing need to improve teaching and learning in ways that diminish student achievement gaps for low-income students and students of color, institutions will need to take into account the challenges associated with learning online that are particularly problematic for these students. Instructional designs and course policies and practices need to work for students with poor internet connectivity, limited access to appropriate devices, family and job responsibilities, and no quiet place at home for doing coursework.

Everyone hopes that college courses rolling out in fall 2020 and beyond will benefit from having some time to shore up their IT infrastructure, design instruction for online delivery, and enhance instructors' online teaching skills. There's an opportunity to do better by students, and seizing that opportunity is a moral imperative and may well be essential for the survival of many higher education institutions. 


\section{References}

Achieving the Dream. (2020, April 2). Network Connection, pp. 2-3.

https://www.achievingthedream.org/sites/default/files/4_2_20_atd_weekly_network_connectio n_covid19_resources_0.pdf

American College and University Educators. (n.d.). ACUE's Online Teaching Toolkit. https://acue.org/online-teaching-toolkit/

Anderson, M., \& Kumar, M. (2019, May 7). Digital divide persists even as lower-income Americans make gains in tech adoption. FactTank. Pew Charitable Trust. https://www. pewresearch.org/facttank/2019/05/07/digital-divide-persists-even-as-lower-income-americans-make-gains-in-techadoption/

Curtin, R., Presser, S., \& Singer, E. (2000). The effects of response rate changes on the index of consumer sentiment. Public Opinion Quarterly, 64, 413-428.

Daempfle, P. A. (2004). An analysis of the high attrition rates among first-year college science, math, and engineering majors. Journal of College Student Retention, 5(1), 37-52.

http://dx.doi.org/10.2190/DWQT-TYA4-T20W-RCWH

Darby, F. (2019, April 17). How to be a better online teacher. The Chronicle of Higher Education. https://www.chronicle.com/article/how-to-be-a-better-online-teacher/\#1

Eccles, J. S. (2009). Who am I and what am I going to do with my life? Personal and collective identities as motivators of action. Educational Psychology, 44, 78-89. https://doi.org/10.1080/00461520902832368

Eddy, S. L., \& Hogan, K. A. (2014). Getting under the hood: How and for whom does increasing course structure work? Life Science Education, 13, 453-468.

Emekalem, A. (2019). Reducing Attrition from STEM Disciplines: Understanding the Student Athlete's Perspective. Peer Review, 21(1/2), 34-37. https://www.aacu.org/peerreview /2019/winterspring/Emekalam

Flaherty, C. (2020, May 8). Reserved: Internet parking. Inside Higher Education. https://www.insidehighered.com/news/2020/05/08/parking-lot-wi-fi-way-life-many-students

Fortenberry, N. L., Sullivan, J. F., Jordan, P. N., \& Knight, D. W. (2007). Engineering education research aids instruction. Science, 317(5842), 1175-1176. http://itll.colorado.

edu/images/uploads/about_us/publications/Papers/SCIENCE\%2OPUBLISHED\%20

VERSION\%202007Aug31.pdf.

Fouad, N. A., Hackett, G., Smith, P. L., Kantamneni, N., Fitzpatrick, M., Haag, S., \& Spencer, D. (2010). Barriers and supports for continuing in mathematics and science: Gender and educational level differences. Journal of Vocational Behavior, 77(3), 361-373.

https://doi.org/10.1016/j.jvb.2010.06.004

Freeman, S., Eddy, S. L., McDonough, M., Smith, M. K., Okoroafor, N., Jordt, H., \& Wenderoth, M. P. (2014). Active learning increases student performance in science, engineering, and mathematics. Proceedings of the National Academy of Sciences. http://www.pnas.org/ content/111/23/8410.full.

Good, C., Rattan, A., \& Dweck, C. S. (2012). Why do women opt out? Sense of belonging and women's representation in mathematics. Journal of Personality and Social Psychology, 102(4), 700. 
Hampton, K. N., Fernandez, L., Robertson, C. T., \& Bauer, J. M. (2020). Broadband and Student Performance Gaps. James H. and Mary B. Quello Center, Michigan State University. https://doi.org/10.25335/BZGY-3V91

Hodges, C., Moore, S., Lockee, B., Trust, T., \& Bond, A. (2020, March 27). The difference between emergency remote teaching and online learning," EDUCAUSE Review.

https://er.educause.edu/articles/2020/3/the-difference-between-emergency-remote-teachingand-online-learning

Johnson, D. R. (2012). Campus racial climate perceptions and overall sense of belonging among racially diverse women in STEM majors. Journal of College Student Development, 53(2), 336-346.

Lichtenstein, G., Chen, H. L., Smith, K. A., \& Maldonado, T. A. (2014). Retention and persistence of women and minorities along the engineering pathway in the United States. In A. Johri and B.M. Olds (Eds.), Cambridge Handbook of Engineering Education Research. New York: Cambridge University Press.

Luskin,B. J. (2019). 12 best practices in online teaching and learning. Psychology Today, Luskin Learning Psychology Series, N, 44. https://www.psychologytoday.com/us/blog/the-media-psychologyeffect/201903/12-best-practices-in-online-teaching-and-learning

Moore, D. L., \& Tarnai, J. (2002). Evaluating nonresponse error in mail surveys. In R. M. Groves, D. A. Dillman, J. L. Eltinge, \& R. J. A. Little (Eds.), Survey Nonresponse, (pp. 197-211). John Wiley \& Sons. National Academies of Sciences, Engineering, and Medicine. (2019). Minority Serving Institutions: America's Underutilized Resource for Strengthening the STEM Workforce. The National Academies Press. https://doi.org/10.17226/25257.

National Academies of Sciences, Engineering, and Medicine. (2018). Indicators for Monitoring Undergraduate STEM Education. The National Academies Press. https://doi.org/10.17226/24943.

O'Keefe, L., Rafferty, J., Gunder, A., \& Vignare, K. (2020, May 18). Delivering high-quality instruction online in response to COVID-19: Faculty playbook. Every Learner Everywhere. http://www.everylearnereverywhere.org/resources

Rainey, K., Dancy, M., Mickelson, R., Stearns, E., \& Moller, S. ( 2018). Race and gender differences in how sense of belonging influences decisions to major in STEM. International Journal of STEM Education, 5(10), https://link.springer.com/article/10.1186/s40594-018-0115-6

Ramsey, L. R., Betz, D. E., \& Sekaquaptewa, D. (2013). The effects of an academic environment intervention on science identification among women in STEM. Social Psychology of Education, 16(3), 377-397.

Salcido, A., \& Cole, J. (2018, September 10). Best practices for teaching online. Teach Online. Arizona State University. https://teachonline.asu.edu/2018/09/best-practices-for-teaching-online/

Smith, J., Lewis, K., Hawthorne, L, \& Hodges, S. (2013). When trying hard isn't natural: Women's belonging with and motivation for male-dominated STEM fields as a function of effort expenditure concerns. Personality and Social Psychology Bulletin, 39(2), 131-143.

Stephens, N. M., Fryberg, S. A.., Markus, H. R., Johnson, C. S., \& Covarrubias, R. (2012). Unseen disadvantage: How American universities' focus on independence undermines the academic performance of first-generation college students. Journal of Personality and Social Psychology, 102( 6), 1178-1197. 
Strayhorn, T. L. (2012). College students' sense of belonging: a key to educational success for all students. Routledge.

Tyton Partners \& Babson Survey Research Group. (2017). Time for Class: Lessons for the Future of Digital Learning in Higher Education. https://tytonpartners.com/library/time-class-2017-2/

Walton, G. M., \& Cohen, G. L. (2011). A brief social-belonging intervention improves academic and health outcomes of minority students, Science, 331(6023): 1447-1451.

Wieman, C. (2017). Improving how universities teach science: Lessons from the Science Education Initiative. Harvard University Press.

Winkelmes, M-A. (2013). Transparency in teaching: Faculty share data and improve students' learning, Liberal Education, 99(2): 48-55.

Winkelmes, M-A., Bernacki, M., Butler, J., Zochowski, M., Golonics, J., \& Weavil, K. H. (2016). A teaching intervention that increases underserved college students' success. Peer Review, 18(1/2). 


\section{Appendix A: Survey Methodology}

The Digital Promise Survey of Student Perceptions of Remote Teaching and Learning was conducted using the nationally representative Ipsos KnowledgePane ${ }^{\circledR}$, for which participants were randomly recruited via address-based sampling to participate in survey research projects online.

The survey was designed to include approximately 1,000 adults studying at a two- or four-year college or university at the undergraduate level, either part- or full-time, who had a class change from including inperson class sessions to instruction completely online because of the COVID-19 pandemic.

Field work was conducted between May 13 and June 1, 2020. Respondents could chose to take the survey in either English or Spanish. Starting May 15, email reminders were sent to non-responders every two days; those who did not respond by May 29th also received a reminder by telephone, and incentives (panel "points" that can redeemed for prizes in future sweepstakes) were increased, first on May 27 and then again on May 29.

Of the 1,709 panelists initially responding, 1,014 were qualified undergraduates taking for-credit college courses that started with in-person classes and later went fully online in spring 2020 . The median completion time of the survey was 10 minutes. Quality control flagged respondents who completed the survey in less than one-third of the median time, removing six cases, for a final sample size of 1,008.

Data were weighted via iterative proportional fitting to the following benchmark distributions of adult undergraduate students with less than a bachelor's degree from the 2018 American Community Survey:

- $\quad$ Gender (male, female) by age (18-20, 21-22, 23-29, 30+)

- Race/ethnicity (White, Black, Other, Hispanic, 2+ races)

- Census region (Northeast, Midwest, South, West)

- Education (high school, some college, associate's degree)

- Household income (less than $\$ 25,000, \$ 25,000-\$ 49,999, \$ 50,000-\$ 74,999, \$ 75,000-\$ 99,999$, $\$ 100,000-\$ 149,999, \$ 150,000+)$

- Language proficiency (English-proficient Hispanic, bilingual or Spanish-proficient Hispanic, nonHispanic)

- Hispanic nativity (U.S.-born, not-U.S.-born, non-Hispanic)

- School type (public, private)

Weights were trimmed at 0.23 percent and 99.77 percent and then rescaled to match the sample size of all respondents. The final weights for qualified respondents (i.e., those who had a class change from inperson to completely online) were extracted from the above weights and re-scaled to sum to the sample size of qualified respondents. The average design effect for the final weight is 1.35 , for a margin of error of 3.6 percentage points for the full sample.

Survey respondents were asked if they were taking a course in a STEM field and if so to answer subsequent survey items with respect to their STEM course (or to the STEM course they considered most consequential for their future if they were taking more than one). Students were asked to indicate the subject area of the course they were describing using a pull-down menu of options with an open- 
response alternative. In some cases, students indicated they were taking a STEM course but wrote in a course subject that was not STEM (for example, history). In other cases, students said they were not taking a STEM course but wrote in a course falling within a STEM field (for example, college algebra). Analysts checked student course subject descriptions and back-coded course descriptions as STEM or non-STEM using the list of STEM subjects shown in Table A-1. After back-coding, the application of sampling weights produced a sample of 638 qualified respondents describing STEM courses.

The margin of error was 4.6 points for students reporting on STEM courses. Error margins are larger for subgroups.

Table A-1. Subject areas coded as STEM

\begin{tabular}{|l|}
\hline Subject Area \\
\hline Agricultural Sciences \\
\hline Astronomy \\
\hline Biology \\
\hline Chemistry \\
\hline Computer Science or Technology \\
\hline Engineering or Engineering Technician \\
\hline Environmental Science \\
\hline Geology \\
\hline Health Professions including Nursing \\
\hline Information Science or Technology \\
\hline Mathematics \\
\hline Physics \\
\hline Statistics or Data Science \\
\hline Other: [TEXT BOX] \\
\hline
\end{tabular}

Table A-2 shows characteristics of the sample of students taking STEM courses compared to the full survey sample of 1,008 and to population data on college undergraduates from the American Community Survey (ACS). 
Table A-2. Characteristics of subset of national sample for survey taking STEM courses before and after applying sample weights

\begin{tabular}{|l|c|c|c|c|c|}
\hline Variable & $\begin{array}{c}\text { STEM Sample } \\
\text { Unweighted }\end{array}$ & $\begin{array}{c}\text { Full Sample } \\
\text { Unweighted }\end{array}$ & $\begin{array}{c}\text { STEM } \\
\text { Sample } \\
\text { Weighted }\end{array}$ & $\begin{array}{c}\text { Full Sample } \\
\text { Weighted }\end{array}$ & ACS \\
\hline$\%$ Female & 61 & 66 & 50 & 55 & 54 \\
\hline$\%$ age 23 or older & 35 & 46 & 33 & 43 & 43 \\
\hline$\%$ Hispanic & 22 & 23 & 22 & 23 & 23 \\
\hline $\begin{array}{l}\text { \% non-Hispanic } \\
\text { White }\end{array}$ & 60 & 59 & 54 & 52 & 51 \\
\hline$\%$ non-Hispanic Black & 9 & 11 & 12 & 15 & 15 \\
\hline $\begin{array}{l}\text { \% Asian, Other, or } \\
\text { Multiple }\end{array}$ & 9 & 8 & 12 & 11 & 11 \\
\hline$\%$ lower income* & 42 & 45 & 33 & 37 & 37 \\
\hline
\end{tabular}

*Household annual income below $\$ 50,000$.

Missingness in data was examined. For items viewed by all participants, missing data (i.e., skipped or refused items) accounted for just $0.7 \%$ of all data, resulting in $99.3 \%$ data coverage. For any one item, missingness ranged from $0 \%$ to $1.6 \%$. The two items with missingness above $1.5 \%$ were examined with univariate tests to determine if any patterns of missingness emerged. There were no significant differences on response for either item related to variables of race/ethnicity, income, gender, age, or location following transition to remote instruction (rural, urban, or suburban). Given the low rate of missingness and the lack of significant differences between student groups who skipped or did not skip items, pairwise deletion (removing a respondent's missing item response from the analysis for that item but not removing the respondent from the analysis of other items) was used to maximize the data available for analysis. 


\section{Appendix B: Survey Items and Response Distribution}

\section{Survey of Student Perceptions of Remote Teaching and Learning - STEM Student Data}

This survey was conducted May 13-June 1, 2020, among a random national sample of 1,008 full- or part-time students enrolled in a two- or four-year college or university who took in-person classes or lectures before the coronavirus outbreak began that were then transitioned completely online. The results below are among the sample of 620 students who took a course in science, technology, engineering, medical/health science or mathematics that moved online. Results have a margin of sampling error of 4.6 points among these students.

The survey was produced for Digital Promise by Langer Research Associates of New York, N.Y., with sampling and data collection by Ipsos Public Affairs via its online, probability-based KnowledgePanel ${ }^{\circledR}$, which provides internet access to randomly recruited participants. The response frequencies below were produced by Langer Research Associates. Due to the nature of missingness described in Appendix A, percentages and statistical analyses for survey items above used only complete data in weighted samples, so distributions of responses outlined below will differ very slightly from the percentages in this report.

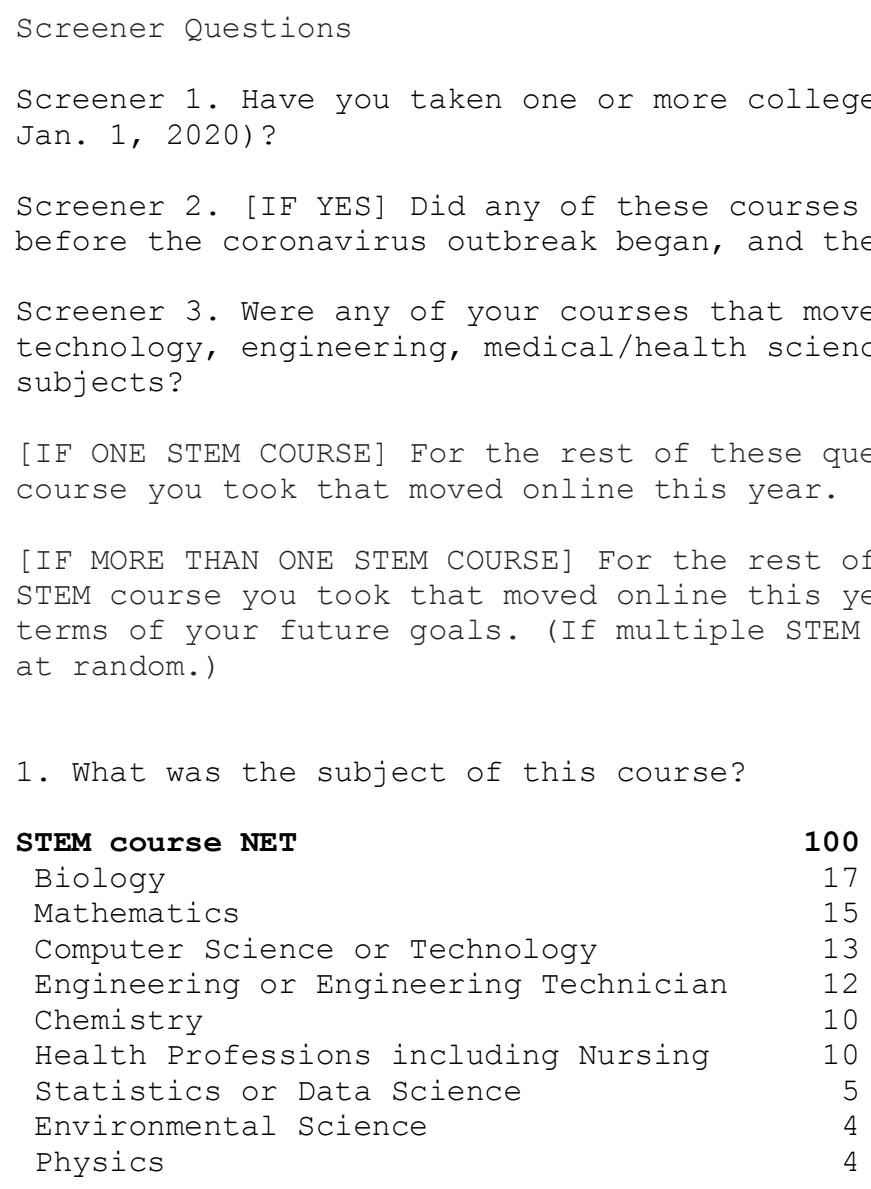


Information Science or Technology

Geology

Agricultural Sciences

Astronomy

Other: STEM course

Skipped

2. Thinking back to when this course included in-person classes, before it moved completely online, how satisfied or dissatisfied were you with the course overall?

$\begin{array}{ccccccc}----- & \text { Satisfied } & ---- & --- & \text { Dissatisfied } & ---- & \\ \text { NET } & \text { Very } & \text { Somewhat } & \text { NET } & \text { Somewhat } & \text { Very } & \text { Skip } \\ 87 & 47 & 40 & 13 & 11 & 2 & 0\end{array}$

3. After this course moved completely online, how satisfied or dissatisfied were you with the course overall?

$\begin{array}{lcccccc}---- & \text { Satisfied } & ---- & --- & \text { Dissatisfied } & ---- & \\ \text { NET } & \text { Very } & \text { Somewhat } & \text { NET } & \text { Somewhat } & \text { Very } & \text { Skip } \\ 57 & 15 & 42 & 42 & 27 & 15 & 1\end{array}$

4. Were you satisfied or dissatisfied with each of these aspects of the course after it moved online?

a. The quality of the instruction

$\begin{array}{lcccccc}----- & \text { Satisfied } & ---- & --- & \text { Dissatisfied } & ---- & \\ \text { NET } & \text { Very } & \text { Somewhat } & \text { NET } & \text { Somewhat } & \text { Very } & \text { Skip } \\ 66 & 25 & 41 & 34 & 24 & 10 & \star\end{array}$

b. The quality of the course content

$\begin{array}{lcccccc}---- & \text { Satisfied } & --- & -- & \text { Dissatisfied } & ---- & \\ \text { NET } & \text { Very } & \text { Somewhat } & \text { NET } & \text { Somewhat } & \text { Very } & \text { Skip } \\ 70 & 26 & 44 & 30 & 23 & 7 & \star\end{array}$

c. The instructor's preparation

$\begin{array}{llclccc}---- & \text { Satisfied } & ---- & --- & \text { Dissatisfied } & ---- & \\ \text { NET } & \text { Very } & \text { Somewhat } & \text { NET } & \text { Somewhat } & \text { Very } & \text { Skip } \\ 74 & 35 & 39 & 26 & 19 & 7 & \star\end{array}$

d. How well you felt you were learning overall

$\begin{array}{lcccccc}----- & \text { Satisfied } & ---- & --- & \text { Dissatisfied } & ---- & \\ \text { NET } & \text { Very } & \text { Somewhat } & \text { NET } & \text { Somewhat } & \text { Very } & \text { Skip } \\ 54 & 14 & 39 & 46 & 28 & 18 & \star\end{array}$

5. Compared with the course when it included in-person classes, was the course after it moved completely online better or worse on each of these items?

a. Your feeling included as a member of the class

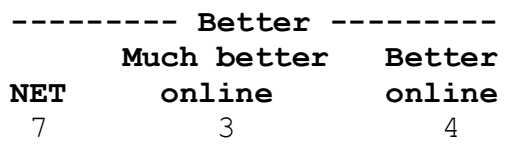

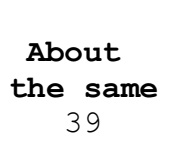

39

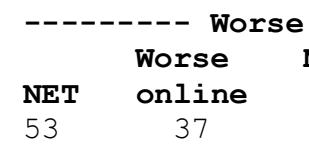

$\mathrm{M}$

Much worse online

16

Skip

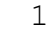


b. Opportunities to collaborate with other students on course work
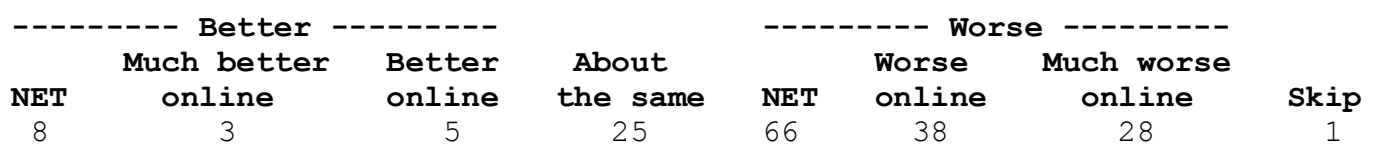

c. The instructor's knowledge of your strengths and weaknesses
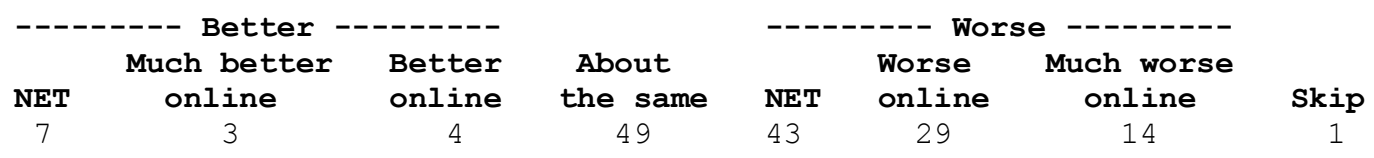

d. The availability of help with the course content

$\begin{array}{lcc}\text { Much better } & \text { Better } \\ \text { NET } & \text { online } & \begin{array}{c}\text { online } \\ 14\end{array} \\ 14 & 4 & 10\end{array}$

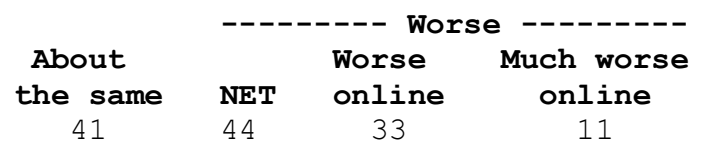

Skip

e. Understanding what was expected of you in the course

\begin{tabular}{|c|c|c|}
\hline NET & $\begin{array}{l}\text { Much better } \\
\text { online }\end{array}$ & $\begin{array}{l}\text { Better } \\
\text { online }\end{array}$ \\
\hline 12 & 4 & 9 \\
\hline
\end{tabular}

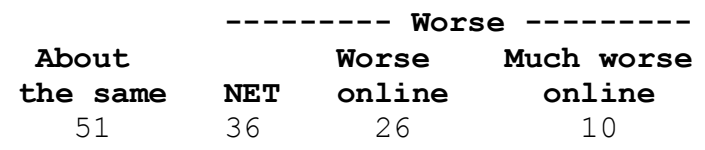

Skip

f. Keeping you interested in the course content
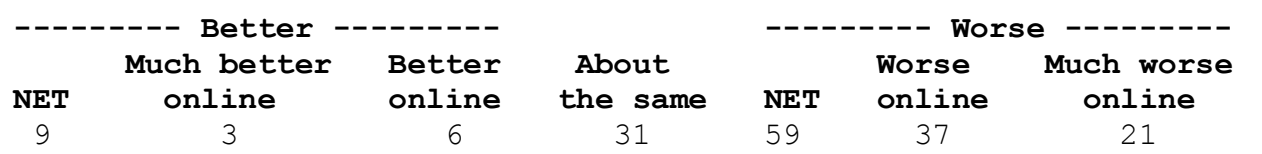

6. After this course moved online, did it include any of the following?

a. Live sessions in which students could ask questions and participate in discussions

$$
\begin{array}{ccc}
\text { Included } & \text { Did not include } & \text { Skip } \\
70 & 29 & 1
\end{array}
$$

b. Live lectures by the instructor, with the class watching in real time

$$
\begin{array}{ccc}
\text { Included } & \text { Did not include } & \text { Skip } \\
60 & 39 & 1
\end{array}
$$

c. Recorded lectures

$$
\begin{array}{ccc}
\text { Included } & \text { Did not include } & \text { Skip } \\
70 & 29 & 1
\end{array}
$$

d. Assignments to meet in "breakout groups" during a live class

$\begin{array}{ccc}\text { Included } & \text { Did not include } & \text { Skip } \\ 23 & 75 & 2\end{array}$


e. Assignments to work on group projects separately from the course meetings

$$
\text { Included Did not include Skip }
$$

$33 \quad 65 \quad 2$

f. Breaking up class activities into shorter pieces than in the previous in-person course

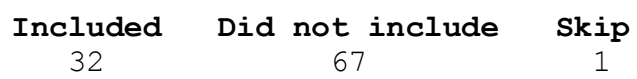

g. The instructor using examples from the real world to illustrate the course content

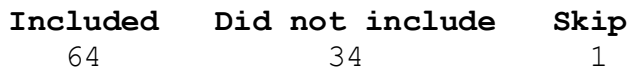

h. Frequent quizzes or other assessments

\section{Included Did not include Skip

$68 \quad 31 \quad 1$

i. Assignments having you express what you had learned and what you still needed to learn

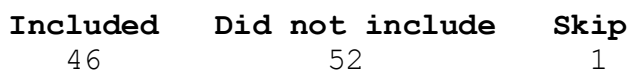

j. Personal messages from the instructor about how you were doing in the course or to make sure you could access course materials

\section{Included Did not include Skip

$\begin{array}{lll}50 & 49 & 1\end{array}$

k. Pre-recorded videos from external sources (e.g., YouTube)

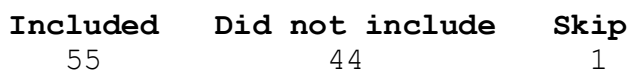

7. In your own words, what would you say was your greatest challenge in learning from this course after it went online?

8. Were these a problem for you, or not a problem, in taking this course after it moved online?

a. Fitting the course in with your home/family responsibilities

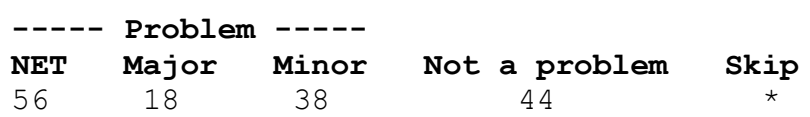

b. Fitting the course in with your work schedule, if you work for pay

$\begin{array}{lcccc}---- & \text { Problem } & ---- & & \\ \text { NET } & \text { Major } & \text { Minor } & \text { Not a problem } & \text { Skip } \\ 31 & 8 & 23 & 69 & 1\end{array}$


c. Feeling too unwell, physically or emotionally, to participate

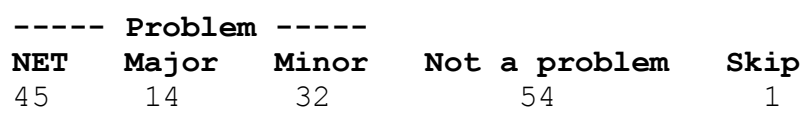

d. Not knowing where to get help with the course

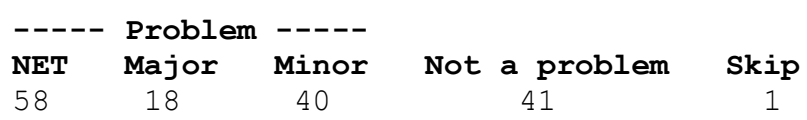

e. Finding a quiet place where you could do the course online

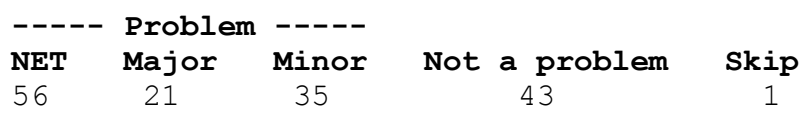

f. Staying motivated to do well in the course

$\begin{array}{lcccc}---- & \text { Problem } & ---- & & \\ \text { NET } & \text { Major } & \text { Minor } & \text { Not a problem } & \text { Skip } \\ 82 & 45 & 37 & 17 & \star\end{array}$

9. What kind of computing device did you use most often for accessing this course after it moved online?

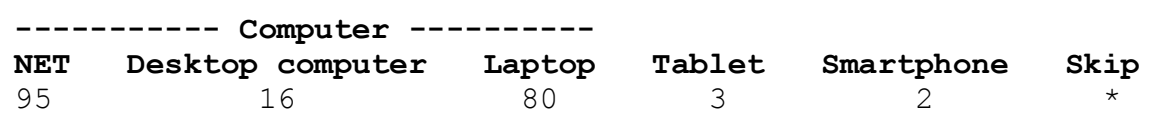

10. [IF ANSWERED Q10] Which best describes this device:

Personal device

$\begin{array}{lcc}\text { A personal device } & \text { A personal device you } \\ 99 & \text { only used by you } & \text { shared with others }\end{array}$

A shared device

in a public place Skip

11. [IF PERSONAL DEVICE SHARED WITH OTHERS] How many people did you share this device with?

Insufficient sample size $(n=48)$.

12. [IF ANY PERSONAL DEVICE] Was this device:

$\begin{array}{cccc}\text { Owned by you } & \text { Provided by the school by someone else } & \begin{array}{c}\text { Owned bip } \\ \text { (other than the school) }\end{array} & \begin{array}{c}\text { Skip } \\ 92\end{array}\end{array}$

13. How did you usually get internet access for this course after it moved online?

\begin{tabular}{ccccc} 
Internet access & at or near your & \multicolumn{2}{c}{ Internet access } & Public access \\
you had at home & home provided & Internet access & in another & \\
already & by the school & at the school & location & Skip \\
95 & 1 & 2 & 1 & 1
\end{tabular}


14. In accessing this course after it moved online, how often, if at all, did you experience serious internet connectivity problems that interfered with your ability to attend or participate?
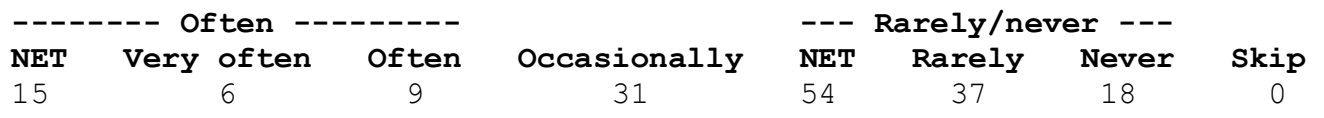

15. How often, if at all, did you experience serious hardware or software problems that interfered with your ability to attend or participate in this course after it moved online?

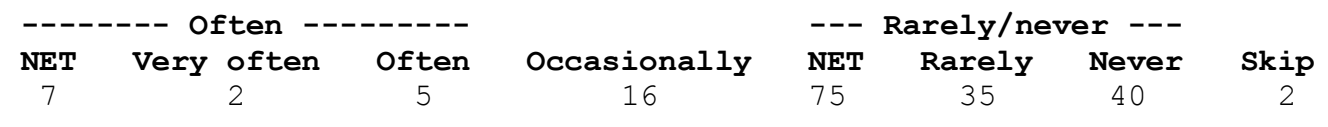

16. During the period that this course was being held online, did any of these get better or worse over time?

a. The quality of the course overall

$\begin{array}{cccc}\text { Got better over time } & \text { No change } & \text { Got worse over time } & \text { Skip } \\ 18 & 55 & 27 & \star\end{array}$

b. Technical problems

$\begin{array}{cccc}\text { Got better over time } & \text { No change } & \text { Got worse over time } & \text { Skip } \\ 21 & 67 & 11 & *\end{array}$

c. The instructor's online teaching skill

$\begin{array}{cccc}\text { Got better over time } & \text { No change } & \text { Got worse over time } & \text { Skip } \\ 29 & 55 & 16 & *\end{array}$

d. Your satisfaction with the course

$\begin{array}{cccc}\text { Got better over time } & \text { No change } & \text { Got worse over time } & \text { Skip } \\ 16 & 53 & 31 & 0\end{array}$

17. In your opinion, which of these do you think was more responsible for any problems you may have experienced with the course after it moved online?

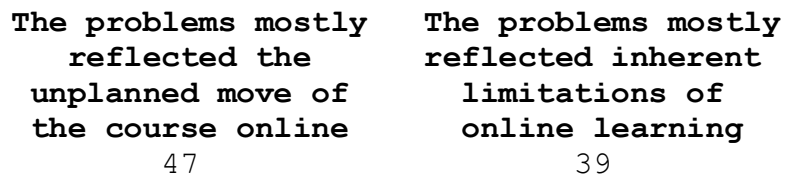

47

The problems mostly
I did not experience

any problems with

the course after it moved online

13

Skip

18. When this course was held in person, how were you taking it?

For a letter grade $\begin{array}{ccc}\text { Pass/fail } & \text { Skip } \\ 92 & 8 & \star\end{array}$ 
19. [IF FOR A LETTER GRADE] When this course moved online, was it...

$$
\begin{aligned}
& \text { Graded, with no option Pass/fail, with no whether to take it } \\
& \text { for pass/fail option for a grade graded or pass/fail Skip } \\
& 33 \\
& 7 \\
& 60
\end{aligned}
$$

$18 / 19$ NET:
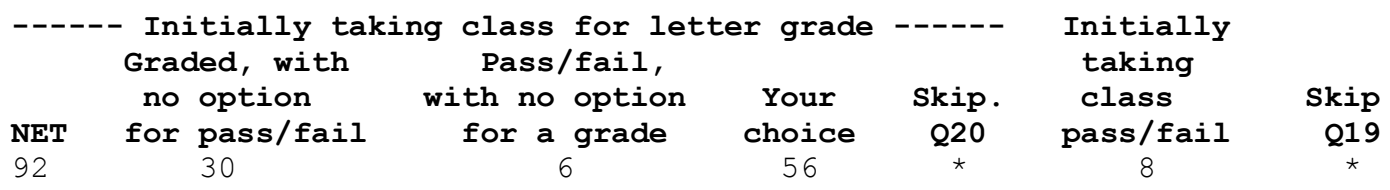

20. [IF PASS/FAIL WITH NO OPTION FOR LETTER GRADE IN Q20] How, if at all, did this change in the grading system affect your motivation to work hard in the course?

Insufficient sample size $(n=31)$.

21. About how many students were enrolled in this course?

$\begin{array}{cccccccc}\text { Fewer than } 35 & 35 & \text { to } 75 & \text { NET } & 76 \text { to } 125 & \text { More than } 125 & \text { Not sure } \\ 50 & 28 & 21 & 10 & & 11 & 0\end{array}$

22. What kind of school offered this course?

$\begin{array}{cccc}\text { 4-year college } & \text { 2-year or community } & & \\ \text { or university } & \text { college } & \text { Other } & \text { Skip } \\ 70 & 29 & 1 & 0\end{array}$

23. Is this a public institution (like a county or state school) or a private school/institute?

$\begin{array}{ccr}\text { Public } & \text { Private } & \text { Skip } \\ 84 & 16 & 0\end{array}$

24. Which best describes your course of study:*

I am majoring in a STEM subject

$6 / 1 / 20$

I am majoring in a different subject, not STEM 29

I have not declared a major

Does not apply

Skip

*Respondents could select both STEM and non-STEM major

25. Before this March, had you previously taken any college courses completely online?

$\begin{array}{cccccc}\text { No, none } & \text { NET } & \text { Yes, one Yes, two to three Yes, four or more } & \text { Skip } \\ 43 & 57 & 20 & 24 & 13 & 1\end{array}$


26. Will you graduate before the fall semester starts?
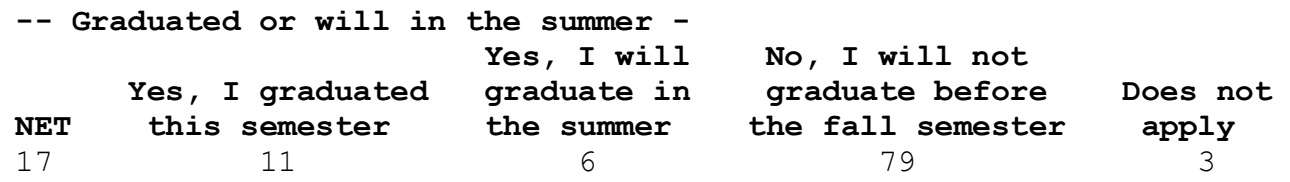

Skip

1

27. [IF NOT GRADUATING BEFORE FALL SEMESTER OR DOES NOT APPLY] Looking ahead to next fall, how likely are you to take another course from the same institution if all its courses are offered online only, at the same cost as in-person courses?

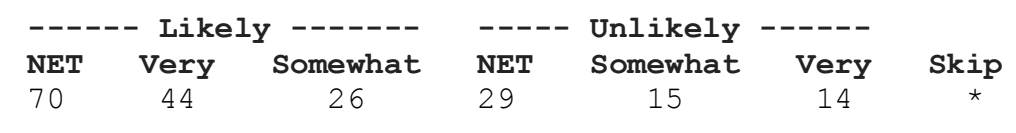

28. [IF NOT GRADUATING BEFORE FALL SEMESTER OR DOES NOT APPLY] Compared with an in-person course, what do you think is a fair price to pay for a completely online course from this institution?

Would take another completely online course at

this institution NET

The same price (100\%) as the in-person course

Three-quarters (75\%) of the price of the in-person course

Half ( $50 \%$ ) the price of the in-person course

One-quarter (25\%) of the price of the in-person course 10

Wouldn't take another completely online course at this

institution regardless of price

Skip

$6 / 1 / 20$

29. If this institution offers online courses next fall, how do you think they will differ, if at all, from your experience this spring? Do you expect online courses in the fall to be...
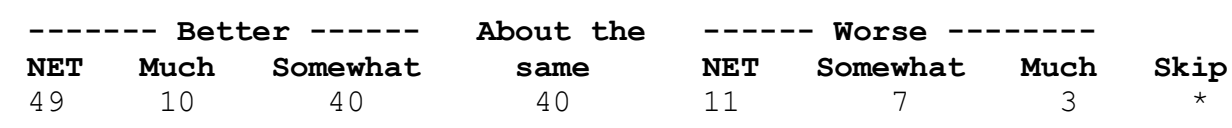

30. While you were taking this college course completely online, did you also work for pay?

$\begin{array}{lcc}\text { Yes } & \text { No } & \text { Skip } \\ 46 & 54 & \star\end{array}$

31. [IF WORKED FOR PAY] How many hours per week did you usually work for pay while you were also taking this college course completely online?

$\begin{array}{ccccccc}1-10 & 11-20 & 21-30 & 31 \text { or more } & \text { Skip } & \text { Mean } & \text { Median } \\ 26 & 30 & 22 & 22 & 1 & 21.8 & 20.0\end{array}$

32. While you were taking this college course completely online, were there any children under age 18 living with you?

$\begin{array}{lcc}\text { Yes } & \text { No } & \text { Skip } \\ 33 & 66 & 1\end{array}$


33. [IF LIVING WITH ANY CHILDREN UNDER 18] Were you responsible for providing care for that child/those children?
Yes No Skip
$3367 *$

$32 / 33$ NET:

\section{No children \\ under 18}

. 66

$\star \star \star \operatorname{END} \star \star \star$

$\begin{array}{lcccc} & & & \\ & \text { Responsible } & \text { Not responsible } & \text { Skip } & \text { Skip } \\ \text { NET } & \text { for care } & \text { for care } & \text { Q34 } & \text { Q33 } \\ 33 & 11 & 22 & * & 1\end{array}$




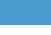

